Article

\title{
First Episode Psychosis and Schizophrenia Are Systemic Neuro-Immune Disorders Triggered by a Biotic Stimulus in Individuals with Reduced Immune Regulation and Neuroprotection
}

\author{
Michael Maes ${ }^{1,2,3, *}$, Kitiporn Plaimas ${ }^{4}(\mathbb{D})$, Apichat Suratanee ${ }^{5}\left(\mathbb{D}\right.$, Cristiano Noto ${ }^{6,7}(\mathbb{D})$ \\ and Buranee Kanchanatawan ${ }^{1}$
}

check for updates

Citation: Maes, M.; Plaimas, K.; Suratanee, A.; Noto, C.; Kanchanatawan, B. First Episode Psychosis and Schizophrenia Are Systemic Neuro-Immune Disorders Triggered by a Biotic Stimulus in Individuals with Reduced Immune Regulation and Neuroprotection. Cells 2021, 10, 2929. https://doi.org/ 10.3390/cells10112929

Academic Editor: Alexander Dityatev

Received: 26 September 2021

Accepted: 24 October 2021

Published: 28 October 2021

Publisher's Note: MDPI stays neutral with regard to jurisdictional claims in published maps and institutional affiliations.

Copyright: (C) 2021 by the authors. Licensee MDPI, Basel, Switzerland. This article is an open access article distributed under the terms and conditions of the Creative Commons Attribution (CC BY) license (https:// creativecommons.org/licenses/by/ $4.0 /)$.
1 Department of Psychiatry, Faculty of Medicine, Chulalongkorn University, Bangkok 10330, Thailand; drburanee@gmail.com

2 Department of Psychiatry, Medical University of Plovdiv, 4000 Plovdiv, Bulgaria

3 IMPACT Strategic Research Center, Deakin University, Geelong 3220, Australia

4 Advanced Virtual and Intelligent Computing (AVIC) Center, Department of Mathematics and Computer Science, Faculty of Science, Chulalongkorn University, Bangkok 10330, Thailand; kplaimas@gmail.com

5 Department of Mathematics, Faculty of Applied Science, King Mongkut's University of Technology North Bangkok, Bangkok 10800, Thailand; apichat.s@sci.kmutnb.ac.th

6 GAPi (Early Psychosis Group), Universidade Federal de São Paulo (UNIFESP), São Paulo 04021-001, Brazil; csnoto@gmail.com

7 Schizophrenia Program (PROESQ), Department of Psychiatry, Universidade Federal de São Paulo (UNIFESP), São Paulo 04021-001, Brazil

* Correspondence: dr.michaelmaes@hotmail.com

Abstract: There is evidence that schizophrenia is characterized by activation of the immune-inflammatory response (IRS) and compensatory immune-regulatory systems (CIRS) and lowered neuroprotection. Studies performed on antipsychotic-naïve first episode psychosis (AN-FEP) and schizophrenia (FES) patients are important as they may disclose the pathogenesis of FES. However, the protein-protein interaction (PPI) network of FEP/FES is not established. The aim of the current study was to delineate a) the characteristics of the PPI network of AN-FEP and its transition to FES; and b) the biological functions, pathways, and molecular patterns, which are over-represented in FEP/FES. Toward this end, we used PPI network, enrichment, and annotation analyses. FEP and FEP/FES are strongly associated with a response to a bacterium, alterations in Toll-Like Receptor-4 and nuclear factor$\mathrm{KB}$ signaling, and the Janus kinases/signal transducer and activator of the transcription proteins pathway. Specific molecular complexes of the peripheral immune response are associated with microglial activation, neuroinflammation, and gliogenesis. FEP/FES is accompanied by lowered protection against inflammation, in part attributable to dysfunctional miRNA maturation, deficits in neurotrophin and Wnt/catenin signaling, and adherens junction organization. Multiple interactions between reduced brain derived neurotrophic factor, E-cadherin, and $\beta$-catenin and disrupted schizophrenia-1 (DISC1) expression increase the vulnerability to the neurotoxic effects of immune molecules, including cytokines and complement factors. In summary: FEP and FES are systemic neuro-immune disorders that are probably triggered by a bacterial stimulus which induces neuroimmune toxicity cascades that are overexpressed in people with reduced anti-inflammatory and miRNA protections, cell-cell junction organization, and neurotrophin and Wnt/catenin signaling.

Keywords: schizophrenia; neuro-immune; inflammation; physiological stress; bacterial translocation; psychiatry; LPS

\section{Introduction}

In 1995, Smith and Maes [1] launched the monocyte-T lymphocyte theory of schizophrenia, which incorporated neurodevelopmental factors and activation of immune pathways 
into a first comprehensive theory of schizophrenia. This theory considered that a neurodevelopmental pathology due to prenatal bacterial or viral infections increases the vulnerability to a later immune-inflammatory hit whereby products of activated macrophages and $\mathrm{T}$ lymphocytes, including cytokines and tryptophan catabolites (TRYCAT), result in neurotoxic effects on brain cells [1]. The presence of an inflammatory process in schizophrenia was first reported in 1997, when Maes et al. [2] showed increased plasma levels of complement component 3 (C3C) and $\mathrm{C} 4$, positive acute phase proteins, including haptoglobin (Hp) [2], and interleukin (IL)-6 [3], one of the cytokines which initiates the acute phase response in schizophrenia. These pioneering findings were replicated in later studies [4], which additionally showed immune-inflammatory processes in the CNS and associations between schizophrenia and immune genes, including single nucleotide polymorphisms in tumor necrosis factor (TNF)- $\alpha[5,6]$.

There is now evidence that schizophrenia phenotypes are accompanied by activation of the immune-inflammatory response system (IRS), including first episode psychosis (FEP), first episode schizophrenia (FES), multiple episode schizophrenia (MES), MES with worsening, the acute phase of schizophrenia, chronic schizophrenia, treatment resistant schizophrenia, deficit schizophrenia, and schizophrenia with comorbid mood symptoms and chronic fatigue-like symptoms [4,7]. In these different phenotypes, IRS activation with increased M1 macrophage, T helper (Th)-1, and Th-17 activation is accompanied by activation of the compensatory immune-regulatory system (CIRS), as indicated by increased levels of immune-regulatory pathways including Th-2 and T regulatory (Treg) cytokines, such as IL-10, IL-4, and IL-13, acute phase reactants, such as Hp, and TRYCAT levels [4,7]. As a consequence, the schizophrenia phenotypes present with a new homeostatic set point between both upregulated IRS and CIRS pathways, although there are indicants that the CIRS prevails in most phenotypes $[4,7,8]$.

Studies on antipsychotic-naïve (AN)-FEP and FES patients are extremely important as the results may disclose the pathogenesis of the disease, and because the results are not affected by the effects of multiple episodes [8]. Moreover, the examination of AN-FEP may disclose causal pathways or molecular processes which are unaffected by the use of antipsychotics. AN-FEP is not only characterized by a cytokine storm with robust M1, Th-1, Th-17, Th-2, and Treg activation, but also by a greater IRS as compared with CIRS response [8]. Moreover, lowered CIRS protection due to relatively lower levels of the immune-regulatory soluble receptors (e.g., IL-2 receptor and TNF receptors) predicts a worse clinical outcome [8]. Furthermore, AN-FEP is accompanied by (a) lowered expression of brain-derived neurotrophic factor (BDNF), disrupted in schizophrenia 1 (DISC1), and ribonuclease III or double-stranded (ds) RNA-specific endoribonuclease (DROSHA) which exert neurotrophic, neuroprotective, and neurogenic functions and modulate microRNA (miRNA) biogenesis $[9,10]$, and (b) lowered activity of paraoxonase (PON)-1, an enzyme with anti-inflammatory, anti-oxidant, and anti-microbial properties [11].

FES, which is the consequence of FEP, is characterized by (a) activated IRS/CIRS with increased levels of CCL11 (or eotaxin, a neurotoxic Th-2-associated cytokine), TRYCATs, oxidative stress indicants, and IL-10; (b) increased IgA C1q circulating immune complexes (CICs); (c) disorders in the expression of $\beta$-catenin, E-cadherin, plasmalemma vesicle associated protein (PLVAP), indicating dysfunctions in cell-cell, adherens, and vascular junctions; (d) increased IgA/IgM responses to Gram-negative bacteria, including Klebsiella pneumoniae [7]; and (e) lowered BDNF [12]. In FEP/FES, increased neurotoxicity due to M1, Th-1, and Th-2 activation contributes to a general cognitive decline (G-CoDe), which reflects abnormalities in brain connectome circuits [13].

As such, schizophrenia is an incredibly complex disease that involves the interaction of genetic factors, immune and intracellular signaling, metabolic pathways, and alterations in proteins/enzymes. Until now, the majority of genetic, pathway, and metabolic studies have concentrated on identifying and characterizing the individual genes, proteins, and metabolics involved in schizophrenia susceptibility. Nevertheless, genes/proteins with small to moderate effects interact to influence susceptibility and outcome in complex 
diseases such as schizophrenia. Network, pathway enrichment, and annotation analysis may provide insight into how genes and proteins interact to influence disease susceptibility [14]. Additionally, protein-protein interaction (PPI) network analysis may reveal novel drug targets for developing novel therapies that modulate pathways and transcription factors [14]. However, no study to date has delineated the characteristics of the PPI network of AN-FEP and its transition to FES, and the most significant paths, molecular patterns, cellular components, and diseases enriched in the PPI networks.

Hence, the aims of the current study were to delineate (a) the interactome or PPI network of FEP/FES and possible sub-networks; (b) the most influential core genes in the interactome, either hubs (disease causing genes) or bottlenecks (controlling the network); (c) the biological functions, pathways, molecular patterns, and cellular components that characterize FEP/FES; (d) the possible trigger factors of the FEP/FES interactome; and (e) the possible pathway similarities with other medical illness.

\section{Methods}

\subsection{Selection of Seed Proteins}

This study is a secondary data analysis on existing data using open, deidentified, and non-coded datasets and, therefore, this is non-human subject research which is not subject to IRB approval. In our previous case-control studies conducted on Brazil and Thai patients with AN-FEP and FES, we identified significant biomarkers or differently expressed genes/proteins (DEPs) as compared with normal controls $[7,9,10,15,16]$. The patients were of both sexes and aged 18-65 years old. The socio-demographic and clinical data are displayed in $[7,9,10,15,16]$. In this study, we examined PPI networks of two related phenotypes, namely AN-FEP and the FEP/FES spectrum, with the latter combining ANFEP and FES data. As such, this study provides information on the onset of schizophrenia (FEP) and the first episode, which is the direct sequel of FEP. Overall, 24 genes/proteins were selected in FEP/FES, namely (shown are the official gene symbols but not italicized): IL4; IL5; IL6; IL10; IL12A; IL13; IFNG (interferon- $\gamma$ ); TNF (tumor necrosis factor- $\alpha$ ); CSF2 (Granulocyte-macrophage colony-stimulating factor); CCL3 (C-C motif chemokine 3); CCL11 (C-C motif chemokine 11 or eotaxin); IL1RN (IL-1 receptor antagonist); C1QA (Complement C1q); PON1 (paraoxonase1); CDH1 (cadherin-1); CTNNB1 (Catenin beta-1); PLVAP (Plasmalemma vesicle-associated protein); BDNF (brain-derived nuclear factor); COMT (Catechol O-methyltransferase); DROSHA (Ribonuclease III double-stranded (ds) RNA-specific endoribonuclease); DISC1 (disrupted in schizophrenia 1 protein); NDEL1 (Nuclear distribution protein nudE-like 1), and MBP (myelin basic protein). The downregulated proteins were: COMT, DISC1, DROSHA, CDH1, CTNNB1, PLVAP, BDNF, and PON1. All other genes were upregulated. There were fifteen FEP-associated seed genes, namely IL5, IL6, IL10, IL12A, IL13, IFNG, TNF, CSF2, NDEL1, MBP, PON1, BDNF, COMT, DROSHA, and DISC1 [7-11,16]. In the present study, we use different identification labels for the same molecules (e.g., IL-6 versus IL6) depending on whether we refer to genes (official PPI gene symbol, e.g., IL6) or proteins (IL-6).

\subsection{PPI Network Construction}

Construction of the PPI network with network expansion was conducted using STRING version 11.0 (https:/ / string-db.org, as accessed 19 September 2021). The STRING database was employed to assess the PPIs (minimum required interaction score was 0.400 ) and to construct zero-order (seed proteins only) and first-order (50 interactions in the first shell, none in the second shell) PPI networks among the genes (set organism is homo sapiens). We examined the network characteristics (number of nodes and edges, average number of neighbors, network diameter and radius, clustering coefficient, and network density, heterogeneity and centralization) of the zero and first-order networks as well as further expanded networks using STRING and Cytoscape (https: / cytoscape.org, as accessed 19 September 2021) plugins including NetworkAnalyzer (Cytoscape App StoreNetworkAnalyzer, as accessed 19 September 2021). Hub nodes were authenticated as the 
top five nodes with the highest degree, and top non-hub bottlenecks as nodes with the highest betweenness centrality. Together they shape the backbone of the network.

Network clustering was carried out to cluster highly interconnected genes to identify protein commonalities with similar attributes and functions. In the present study, we employed STRING to perform Markov Clustering (MCL), which robustly identifies annotated complexes, and Cytoscape plugins, namely ClusterMaker. Molecular Complex Detection (MCODE) was performed using Metascape to detect smaller components of densely connected nodes which represent molecular complexes [17].

\subsection{Enrichment Analysis}

The list of seed and first-order genes (divided into communities by cluster analysis and up-and downregulated genes) were extended with known protein interactions from STRING, IntAct (https://www.ebi.ac.uk/intact/, as accessed 19 September 2021), GOnet (https://tools.dice-database.org/Gonet/, as accessed 19 September 2021), Metascape (http:/ / metascape.org, as accessed 19 September 2021), inBio Discover (https: / inbio-discover. $\mathrm{com} /$, as accessed 19 September 2021), Enrichr (https://maayanlab.cloud/Enrichr/, as accessed 19 September 2021), or the R package ClusterProfiler 4.0 and examined for their pathway, function, or disease enrichment scores. In this study, we use the false discovery rate (FDR) corrected $p$-values. We searched the networks against GO biological processes (assemblies of molecular functions in pathways), GO molecular functions (protein activities at the molecular level), GO cellular component (location of the proteins) (www.geneontology. org, as accessed 19 September 2021), Kyoto Encyclopedia of Genes and Genomes (KEGG) pathways (https://genome.jp/kegg/, as accessed 19 September 2021), REACTOME (the European Bio-informatics Institute pathway database) (https://reactome.org, as accessed 19 September 2021), Translational Regulatory Relationships (TTRUST) (www.grnpedia.org, as accessed 19 September 2021), and DOID human disease phenotypes (Disease OntologyInstitute for Genome Sciences @ University of Maryland (disease-ontology.org, as accessed 19 September 2021). Moreover, Metascape was used to delineate and visualize the GO biological pathways and molecular processes, and PANTHER (PANTHER-Gene List Analysis (pantherdb.org), as accessed 19 September 2021), REACTOME, KEGG, and Wiki (WikiPathwaysWikiPathways, as accessed 19 September 2021) pathways, which are over-represented in the gene sets. Metascape automatically clusters, hierarchically, the significant terms into a tree based on Kappa-statistical similarities among their gene memberships. This is useful because GO terms heavily overlap and, therefore, output GO terms show a large degree of redundancy. The top 10 performing terms obtained with Enrichr are displayed as bar graphs produced with Appyters.

\subsection{Annotation Analysis and Annotation Visualization}

Annotation analysis was employed to examine GO terms annotating the genes/proteins assembled into functional sets. GOnet analysis was employed to construct interactive graphs which, at the same time, contain genes and GO terms. Furthermore, we made custom GO term annotation lists consisting of the most representative GO terms (by preference, the significant children). inBio Discover was used to show the network with the top 4 selected DOID annotations. $R$ package ClusterProfiler was employed to make dot plots of annotated GO term leaves, with size of the dots indicating gene number and color of the dots indicating the $p$-values.

\section{Results}

\subsection{The PPI Network Topography of FEP and FES/FEP}

All genes/proteins were used to construct an undirected network representing the protein interactions of FEP/FES. The zero-order network consisted of 23 nodes, and the number of edges $(n=88)$ exceeded the expected number of edges $(n=24)$, with p-enrichment value of $1.0 \times 10^{-16}$, and average node degree $=7.65$ and average local clustering coefficient $=0.709$. There were three singletons, namely PLVAP, DROSHA, and 
C1QA. Figure 1 displays the first order protein network that showed one singleton (PLVAP) and 92 nodes; the number of edges $(n=1063)$ exceeded the expected number of edges $(n=273)$ with p-enrichment value of $1.0 \times 10^{-16}$, average node degree $=23.1$, average local clustering coefficient $=0.678$, average number of neighbors $=23.109$, network diameter $=4$ and radius $=2$, characteristic path length $=1.919$, network density $=0.254$, and heterogeneity $=0.586$.

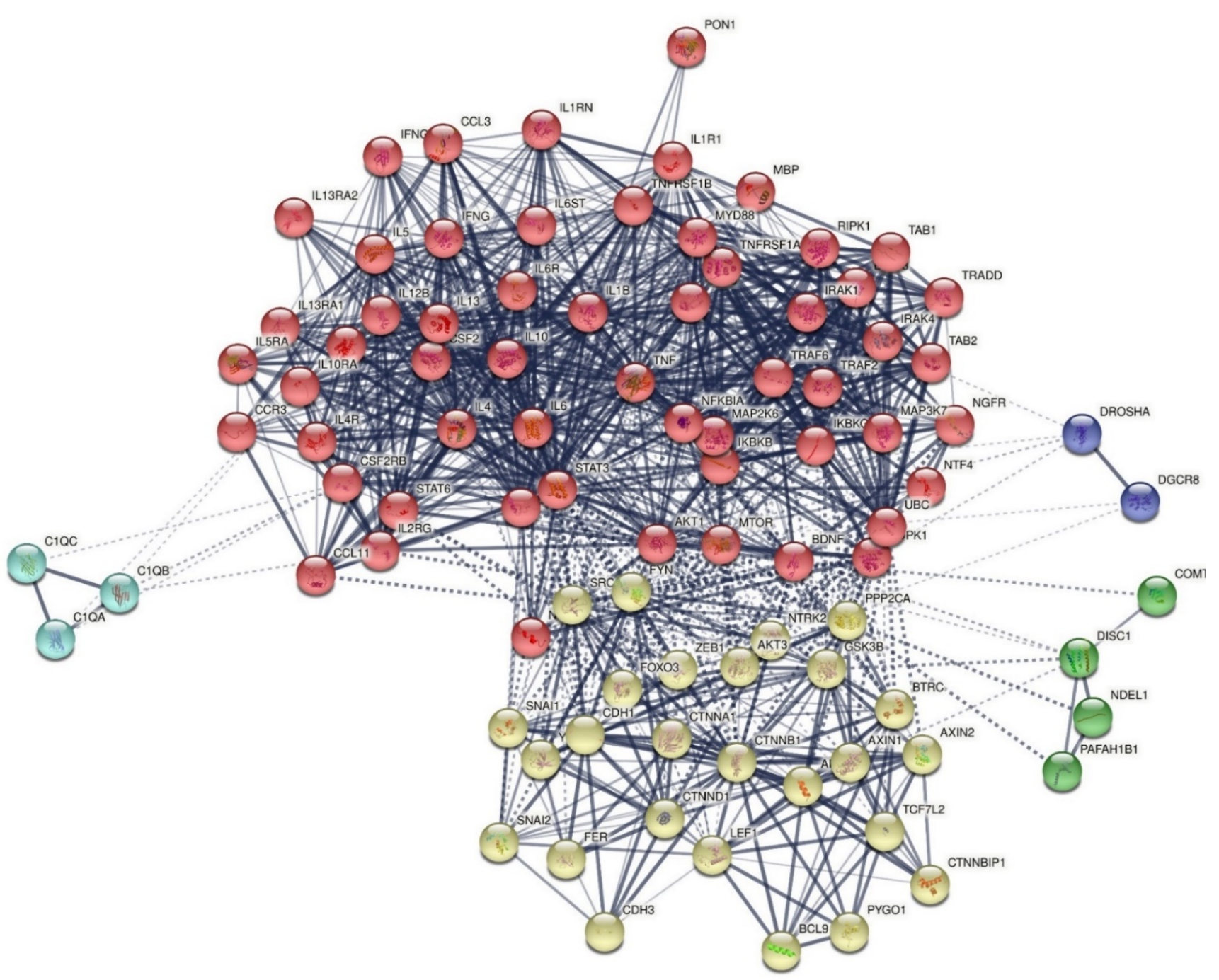

Figure 1. First order protein network showing 92 nodes and 1063 edges. MCL cluster analysis detected two clusters: (1) a first immune cluster (red color) was centered around BDNF, CCL11, CCL3, CSF2, IFNG, IL10, IL12A, IL13, IL1R1, IL4, IL5, IL6, MBP, PON1, and TNF, and (2) a second adhesion-associated cluster (yellow nodes) was centered around CDH1 and CTNNB1. 
Hub and betweenness analysis showed that IL6 (degree = 62), TNF (58), IL10 (46), IL4 (42), and CSF2 (39) were the top five hubs, while CTNNB1 (betweenness centrality $=0.0449$ ), BDNF (0.0285) and CDH1 (0.014) were the top three non-hub bottlenecks. Top rank hubs and bottlenecks (computed as $\mathrm{z}$ degree $+\mathrm{z}$ betweenness) computed for the selected 23 seed proteins in a further enlarged network showed that the most influential proteins were in descending order of importance: CTNNB1, IL6, TNF, CDH1, IL4, IL10, and BDNF.

Figure 1 shows the results of MCL cluster analysis with an inflation parameter $=2.5$. Two protein communalities were detected: (1) a first immune cluster was centered around CCL11, CCL3, CSF2, IFNG, IL10, IL12A, IL13, IL1R1, IL4, IL5, IL6, MBP, PON1, TNF, and BDNF; and (2) a second cell-cell junction-associated cluster was centered around CDH1 and CTNNB1. In the first-order network, there were two switches connecting these clusters. The first bridge was CDH1, which belongs to cluster 2 and is connected with CTNNB1 and with five seed genes in cluster 1 (CSF2, IL4, TNF, IL10, and IL6). In the first-order network, CHD1 shows 11 connections with cluster 1 seed genes and 16 with cluster 2 seed genes. The second switch was BDNF, which belongs to cluster 1 and shows interconnections with five cluster 1 genes, namely IL6 (0.811), TNF (0.805), IL4 (0.695), IL10 (0.613), and IFNG (0.419) and with one cluster 2 gene, namely CTNBB1 (0.932). In the first-order network, BDNF shows 16 connections (at $>0.40$ ) with cluster 1 genes and 7 with cluster 2 genes. More specifically, BDNF shows interconnections at $>0.900$ with four cluster 1 genes, namely STAT3 (0.967), TRAF6 (0.926), NTF4 (0.993), and NGFR (0.996), and three cluster 2 genes, namely NTRK2 (0.998), CTNNA1 (0.910), and CTNND1 (0.907). Moreover, BDNF showed interactions with COMT (0.733) and DISC1 (0.640) which do not belong to either cluster 1 or 2. We observed that AKT1, which belongs to cluster 1 in the first-order network, might be another switch, as it was interconnected with 11 cluster 1 seed proteins and with CTNNB1 and CDH1.

The seed proteins were used to construct a PPI network representing the protein interactions in FEP only. The first-order network (first shell) shows 65 nodes, the number of edges $(n=811)$ exceeded the expected number of edges $(n=193)$ with p-enrichment value of $1.0 \times 10^{-16}$, with average node degree $=25$, average local clustering coefficient $=0.75$, average number of neighbors $=24.954$, network diameter $=4$ and radius $=2$, characteristic path length $=1.780$, network density $=0.390$, and heterogeneity $=0.549$. The top five hubs are, in descending order of importance, IL6 (87), TNF (85), IL10 (71), IL4 (71), and IFNG (68). BDNF was the most important bottleneck (0.0563), followed by IL6 (0.0473) and TNF (0.046).

\subsection{Enrichment Analysis in FEP}

Figure 2 (upregulated genes) and Figure 3 (downregulated genes) show heat maps (bar graphs) with the top 20 biological function GO enriched terms in FEP (shown are accumulative hypergeometric $p$-values). Figure 2 shows that the most important GO terms over-represented in the upregulated genes were: inflammatory response and cytokine production, and response to LPS and receptor signaling pathway via JAK-STAT. Figure 3 shows that the most important GO terms over-represented in the downregulated genes were: neurotrophin signaling pathway, production of miRNA involved in gene silencing, and neuron projection morphogenesis. 


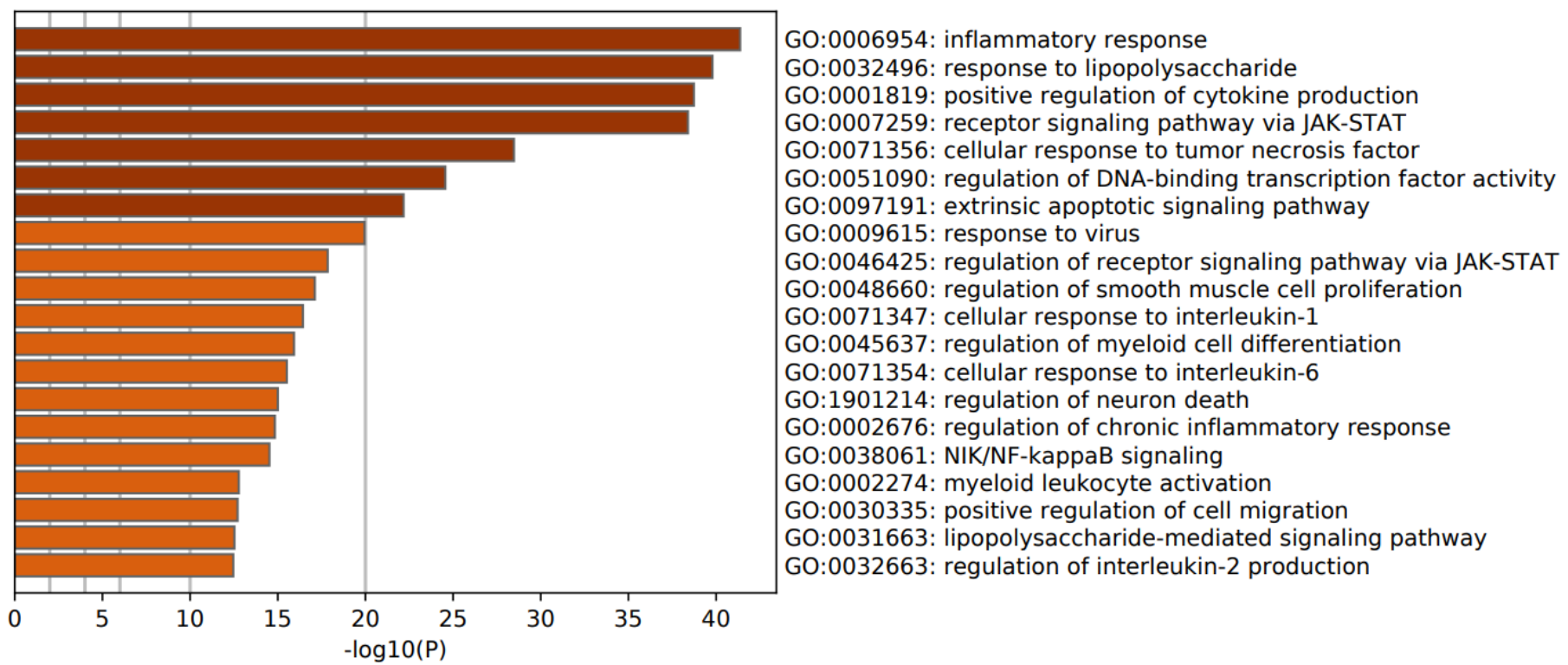

Figure 2. Heat map of enriched GO terms showing the top 20 biological functions overexpressed in the upregulated proteins of patients with first episode psychosis (accumulative hypergeometric $p$-values).

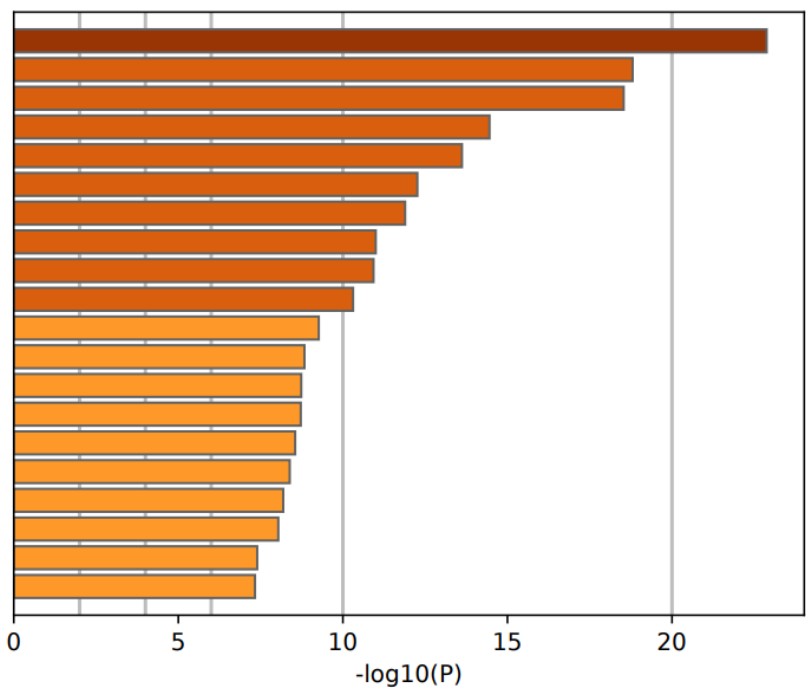

GO:0038179: neurotrophin signaling pathway

GO:0035196: production of miRNAs involved in gene silencing by miRNA

GO:0048812: neuron projection morphogenesis

GO:1901615: organic hydroxy compound metabolic process

GO:0033674: positive regulation of kinase activity

GO:0120035: regulation of plasma membrane bounded cell projection organization

GO:0010942: positive regulation of cell death

GO:0071417: cellular response to organonitrogen compound

GO:0007265: Ras protein signal transduction

GO:0097190: apoptotic signaling pathway

GO:2000251: positive regulation of actin cytoskeleton reorganization

GO:0048511: rhythmic process

GO:0006584: catecholamine metabolic process

GO:0044089: positive regulation of cellular component biogenesis

GO:0048514: blood vessel morphogenesis

GO:1903827: regulation of cellular protein localization

GO:0060148: positive regulation of posttranscriptional gene silencing

GO:0061061: muscle structure development

GO:0048013: ephrin receptor signaling pathway

GO:0070371: ERK1 and ERK2 cascade

Figure 3. Heat map of enriched GO terms showing the top 20 biological functions associated with the downregulated proteins of patients with first episode psychosis (accumulative hypergeometric $p$-values).

Table 1 shows the biological interpretation of the MCODE analysis performed using multiple databases (GO biological and molecular, KEGG, WikiPaths, PANTHER, and REACTOME gene sets) in FEP. MCODE performed on the upregulated genes in FEP detected one cluster which represented a response to LPS, response to molecule of bacterial origin, and inflammatory response. A second MCODE analysis conducted on the upregulated genes revealed two molecular complexes, namely signaling by interleukins and a second, which is shown in Table 1, representing TNFR1-induced NFKB signaling pathway, death receptor signaling, and TNF signaling. MCODE performed on the downregulated genes in FEP detected two small complexes, which represented: (1) neurotrophin/tropomyosin related kinase B (TrkB) signaling pathway and cellular component morphogenesis; and (2) RNA interference, production of miRNAs involved in gene silencing by miRNA, and production of small RNA involved in gene silencing by RNA. The search for a regulatory relationship using TTRUST (in Metascape) shows that the top two over-represented tran- 
scriptional networks in the upregulated FEP network are regulated by RELA (TRR0115, $\log 10 p=-38)$ and NFKB1 (TRR00875, $\log 10 p=-34)$.

Table 1. Results of Molecular Complex Detection (MCODE) analysis performed on upregulated and downregulated differentially expressed proteins in first episode psychosis (FEP) and/or first episode schizophrenia (FES).

\begin{tabular}{|c|c|c|c|}
\hline MCODE Components & GO ID & Biological Term & $\log 10(p)$ \\
\hline \multirow{3}{*}{$\begin{array}{l}\text { Upregulated genes in FEP, MCODE1 } \\
\text { (Biological GO terms) }\end{array}$} & GO:0032496 & response to lipopolysaccharide & -41.6 \\
\hline & GO:0006954 & inflammatory response & -40.8 \\
\hline & GO:0002237 & $\begin{array}{c}\text { response to molecule of bacterial } \\
\text { origin }\end{array}$ & -40.8 \\
\hline \multirow{3}{*}{$\begin{array}{l}\text { Upregulated genes in FEP, MCODE2 } \\
\text { (GO, PANTHER, KEGG, WikiPaths) }\end{array}$} & R-HSA-5357956 & $\begin{array}{l}\text { TNFR1-induced NFkappaB signaling } \\
\text { pathway }\end{array}$ & -10.1 \\
\hline & R-HSA-73887 & death receptor signaling & -9.8 \\
\hline & R-HSA-75893 & TNF signaling & -9.4 \\
\hline \multirow{3}{*}{$\begin{array}{l}\text { Downregulated genes in FEP, } \\
\text { MCODE1 (Biological GO terms) }\end{array}$} & GO:0048011 & $\begin{array}{l}\text { neurotrophin TRK receptor signaling } \\
\text { pathway }\end{array}$ & -22.5 \\
\hline & GO:0007169 & $\begin{array}{l}\text { transmembrane receptor protein } \\
\text { tyrosine kinase signaling pathway }\end{array}$ & -22.1 \\
\hline & GO:0032989 & cellular component morphogenesis & -21.8 \\
\hline \multirow{3}{*}{$\begin{array}{l}\text { Downregulated genes in FEP, } \\
\text { MCODE2 (Biological GO terms) }\end{array}$} & GO:0016246 & RNA interference & -15.6 \\
\hline & GO:0035196 & $\begin{array}{l}\text { production of miRNAs involved in } \\
\text { gene silencing by miRNA }\end{array}$ & -15.5 \\
\hline & GO:0070918 & $\begin{array}{l}\text { production of small RNA involved in } \\
\text { gene silencing by RNA }\end{array}$ & -15.3 \\
\hline \multirow{3}{*}{$\begin{array}{l}\text { All seed genes in FEP/FES, MCODE1 } \\
\text { (Biological GO terms) }\end{array}$} & GO:0001774 & microglial cell activation & -13.2 \\
\hline & GO:0042531 & $\begin{array}{l}\text { positive regulation of tyrosine } \\
\text { phosphorylation of STAT protein }\end{array}$ & -12.3 \\
\hline & GO:0042509 & $\begin{array}{c}\text { regulation of tyrosine } \\
\text { phosphorylation of STAT protein }\end{array}$ & -11.8 \\
\hline
\end{tabular}

\subsection{Enrichment Analysis in FEP/FES}

Figure 4 shows a heat map with the top 20 biological GO enriched terms in the first FEP/FES cluster, indicating that the most important over-represented terms were: inflammatory response, positive regulation of cytokine production, I-kappa kinase/NFKB signaling, and a response to LPS. Figure 5 shows a heat map with the top 20 biological GO enriched terms in the second cluster of FEP/FES, namely Wnt signaling pathway, cell-cell junction organization, and beta-catenin-TCF complex assembly. Table 2 shows the top GP enriched terms in the complement factors, DISC1 and DROSHA. 


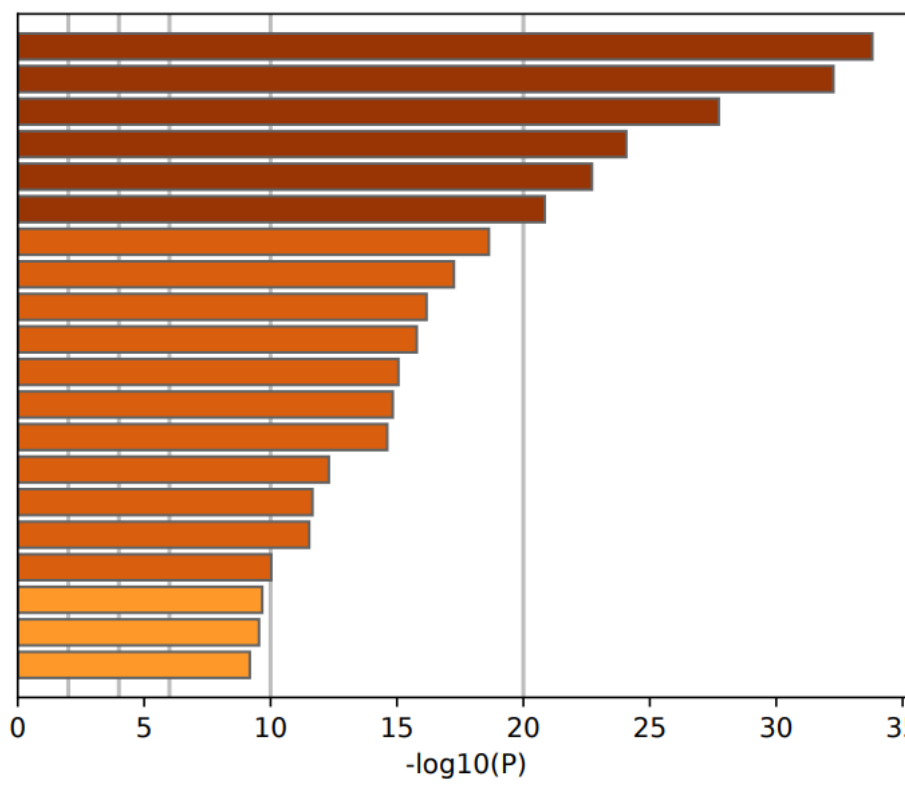

GO:0006954: inflammatory response

GO:0001819: positive regulation of cytokine production GO:0007249: I-kappaB kinase/NF-kappaB signaling GO:0032496: response to lipopolysaccharide GO:0007259: receptor signaling pathway via JAK-STAT GO:0097191: extrinsic apoptotic signaling pathway GO:0001959: regulation of cytokine-mediated signaling pathway GO:0010942: positive regulation of cell death

GO:0042116: macrophage activation GO:0030335: positive regulation of cell migration GO:0032755: positive regulation of interleukin-6 production GO:0038061: NIK/NF-kappaB signaling GO:0070997: neuron death GO:0001568: blood vessel development GO:1903530: regulation of secretion by cell

GO:0071363: cellular response to growth factor stimulus GO:0006809: nitric oxide biosynthetic process GO:0048871: multicellular organismal homeostasis GO:0002639: positive regulation of immunoglobulin production GO:0010506: regulation of autophagy

Figure 4. Heat map of enriched GO terms showing the top 20 biological functions in the first FEP/FES gene cluster (accumulative hypergeometric $p$-values).

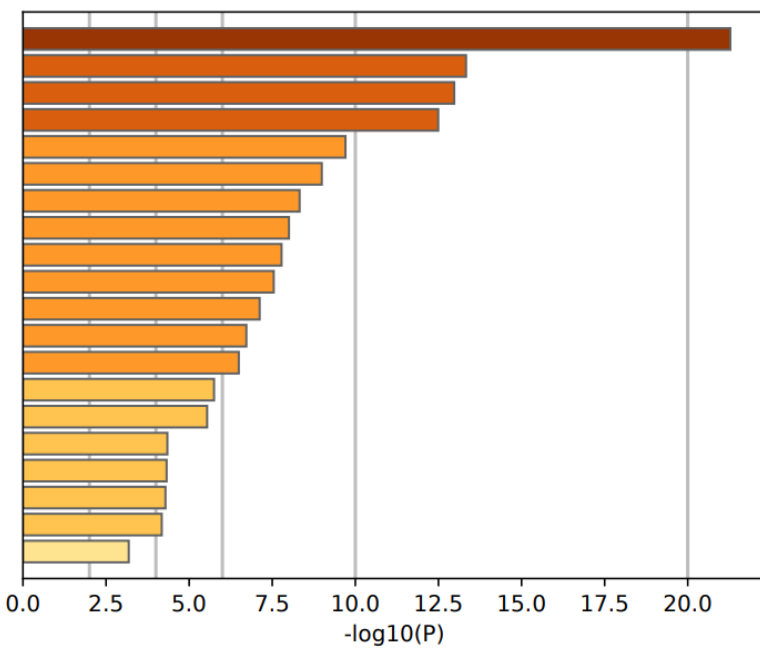

GO:0016055: Wnt signaling pathway GO:0045216: cell-cell junction organization GO:1904837: beta-catenin-TCF complex assembly GO:0001837: epithelial to mesenchymal transition

GO:2001237: negative regulation of extrinsic apoptotic signaling pathway GO:0071407: cellular response to organic cyclic compound

GO:0071680: response to indole-3-methanol

GO:0043393: regulation of protein binding

GO:1903997: positive regulation of non-membrane spanning protein tyrosine kinase activity GO:0010942: positive regulation of cell death

GO:0007169: transmembrane receptor protein tyrosine kinase signaling pathway

GO:0048754: branching morphogenesis of an epithelial tube

GO:2000811: negative regulation of anoikis

GO:0045596: negative regulation of cell differentiation

GO:0042476: odontogenesis

GO:0050673: epithelial cell proliferation

GO:0051090: regulation of DNA-binding transcription factor activity

GO:0007260: tyrosine phosphorylation of STAT protein

GO:0032091: negative regulation of protein binding

GO:0030855: epithelial cell differentiation

Figure 5. Heat map of enriched GO terms showing the top 20 biological functions in the second FEP/FES gene cluster (accumulative hypergeometric $p$-values).

Electronic Supplementary File (ESF) Figure S1 shows a bar graph with the top 10 performing cellular GO terms which were accumulated in FEP/FES genes, indicating that the catenin complex, and cytoplasmatic and vesicle membranes were the most significant cellular terms. ESF Figure S2 shows the top 10 performing REACTOME terms accumulated in the FEP/FES gene list, indicating that the first terms pointed towards an immune response and that the top 7-10 terms pointed towards different aspects of Toll-Like Receptor (TLR) 3/4 signaling. ESF Figure S3 displays the top 10 PANTHER terms, which were over-expressed in the FEP/FES gene list with CCKR, TLR, apoptosis, Wnt, and cadherin signaling as top pathways. ESF Figure S4 displays the top 10 WikiPathway terms which were over-expressed in the FEP/FES gene list, including TLR4 signaling and miRNA involvement. 
Table 2. Biological GO term classifications of differently expressed proteins in first episode psychosis or schizophrenia.

\begin{tabular}{|c|c|c|c|c|c|}
\hline $\begin{array}{l}\text { Top } \\
\text { Genes }\end{array}$ & GO Term ID & GO Term Definition & $P$ & $\begin{array}{c}p \text { FDR } \\
\text { Adjusted }\end{array}$ & $\begin{array}{l}\text { Number } \\
\text { of Genes }\end{array}$ \\
\hline \multicolumn{6}{|c|}{ Complement factors } \\
\hline 1 & GO:0098883 & synapse pruning & $1.00 \times 10^{-10}$ & $1.41 \times 10^{-6}$ & 3 \\
\hline 2 & GO:0030449 & regulation of complement activation & $2.02 \times 10^{-10}$ & $1.11 \times 10^{-3}$ & 3 \\
\hline 3 & GO:0002920 & regulation of humoral immune response & $3.18 \times 10^{-7}$ & $1.17 \times 10^{-3}$ & 3 \\
\hline 4 & GO:0006958 & complement activation, classical pathway & $5.40 \times 10^{-7}$ & $1.30 \times 10^{-3}$ & 3 \\
\hline 5 & GO:0002455 & humoral immune response mediated by circulating immunoglobulin & $5.92 \times 10^{-7}$ & $1.30 \times 10^{-3}$ & 3 \\
\hline 6 & GO:0006956 & complement activation & $7.29 \times 10^{-7}$ & $1.34 \times 10^{-3}$ & 3 \\
\hline 7 & GO:0016064 & immunoglobulin mediated immune response & $1.08 \times 10^{-6}$ & $1.56 \times 10^{-3}$ & 3 \\
\hline 8 & GO:0019724 & B cell mediated immunity & $1.13 \times 10^{-6}$ & $1.56 \times 10^{-3}$ & 3 \\
\hline 9 & GO:0002449 & lymphocyte mediated immunity & $2.35 \times 10^{-6}$ & $2.66 \times 10^{-3}$ & 3 \\
\hline 10 & GO:0050808 & synapse organization & $2.46 \times 10^{-6}$ & $2.66 \times 10^{-3}$ & 3 \\
\hline \multicolumn{6}{|c|}{ DISC1 } \\
\hline 1 & GO:0021799 & cerebral cortex radially oriented cell migration & $1.13 \times 10^{-8}$ & $1.25 \times 10^{-4}$ & 3 \\
\hline 2 & GO:0021795 & cerebral cortex cell migration & $3.82 \times 10^{-8}$ & $1.40 \times 10^{-4}$ & 3 \\
\hline 3 & GO:0045773 & positive regulation of axon extension & $3.82 \times 10^{-8}$ & $1.40 \times 10^{-4}$ & 3 \\
\hline 4 & GO:0022029 & telencephalon cell migration & $9.56 \times 10^{-8}$ & $2.46 \times 10^{-4}$ & 3 \\
\hline 5 & GO:0021885 & forebrain cell migration & $1.11 \times 10^{-7}$ & $2.46 \times 10^{-4}$ & 3 \\
\hline 6 & GO:0021954 & central nervous system neuron development & $2.54 \times 10^{-7}$ & $4.67 \times 10^{-4}$ & 3 \\
\hline 7 & GO:0050772 & positive regulation of axonogenesis & $3.06 \times 10^{-7}$ & $4.81 \times 10^{-4}$ & 3 \\
\hline 8 & GO:0030516 & regulation of axon extension & $4.42 \times 10^{-7}$ & $6.09 \times 10^{-4}$ & 3 \\
\hline 9 & GO:0061387 & regulation of extent of cell growth & $6.67 \times 10^{-7}$ & $8.17 \times 10^{-4}$ & 3 \\
\hline 10 & GO:0021987 & cerebral cortex development & $7.83 \times 10^{-7}$ & $8.48 \times 10^{-4}$ & 3 \\
\hline \multicolumn{6}{|c|}{ DROSCHA } \\
\hline 1 & GO:0031053 & primary miRNA processing & $1.84 \times 10^{-7}$ & $2.03 \times 10^{-3}$ & 2 \\
\hline 2 & GO:0010586 & miRNA metabolic process & $1.18 \times 10^{-6}$ & $5.95 \times 10^{-3}$ & 2 \\
\hline 3 & GO:0035196 & production of miRNAs involved in gene silencing by miRNA & $2.08 \times 10^{-6}$ & $5.95 \times 10^{-3}$ & 2 \\
\hline 4 & GO:0070918 & production of small RNA involved in gene silencing by RNA & $2.70 \times 10^{-6}$ & $5.95 \times 10^{-3}$ & 2 \\
\hline 5 & GO:0031050 & dsRNA processing & $2.70 \times 10^{-6}$ & $5.95 \times 10^{-3}$ & 2 \\
\hline
\end{tabular}

Table 1 shows the results of a MCODE analysis performed on all FEP/FES genes and detected a molecular complex (with core genes IFNG, IL6, CCL3, IL4, IL12A, and IL13), which represented microglial cell activation, positive regulation of tyrosine phosphorylation of STAT protein, and regulation of tyrosine phosphorylation of STAT protein. Annotation analysis also shows that a neuroinflammatory response (GO:0150076, $\mathrm{pFDR}=1.0 \times 10^{-7.13}$ ) was accumulated in the seed gene list selection. It is interesting to note that behavior (GO:0007610; $\log 10 p=-4.941 ; 10$ overlapping genes) and learning and memory (GO:0007611; $\log 10 p=-4.908 ; 7$ overlapping genes) accumulated in the FEP/FES genes.

ESF Figure S5 shows a network built with OmicsNet (using InAct; 2581 nodes, 4154 edges, 86 seeds). The top three over-represented transcriptional TTRUST networks were: SP1 (132 hits), NFKB1 (95), and RELA (95).

\subsection{Annotation Analysis and Visualization}

Figure 6 shows the results of GOnet annotation visualization in FEP/FES, depicting the seed protein nodes and the top $10 \mathrm{GO}$ terms (or their most important children). As expected, the 
GO terms comprised key immune processes, including cytokine mediated signaling pathway (GO:0019221, pFDR $<1 \times 10^{-10}$ ), type-2 immune response (GO:0042092, pFDR $=6.42 \times 10^{-4}$ ), positive regulation of $\mathrm{T}$ cell activation (GO: 0050870, $\mathrm{pFDR}=6.384 \times 10^{-4}$ ), positive regulation of $\mathrm{B}$ cell proliferation (GO:0030890, $\mathrm{pFRD}=2.062 \times 10^{-4}$ ), positive regulation of immunoglobulin production (GO:0002639, $\mathrm{pFDR}=3.00 \times 10^{-6}$ ), and positive regulation of myeloid leukocyte differentiation (GO:0002763, pFDR $=4.389 \times 10^{-4}$ ). Moreover, other important GO terms were: cellular response to LPS (GO:0071222, pFDR $=1.520 \times 10^{-8}$ ), microglial cell activation (GO:0001774, $\left.\mathrm{pFDR}=8.875 \times 10^{-7}\right)$, positive regulation of gliogenesis $\left(\mathrm{pFDR}=7.962 \times 10^{-4}\right)$, and positive regulation of tyrosine phosphorylation of STAT protein (GO:0042531, pFDR $\left.=1 . \times 10^{-10}\right)$.

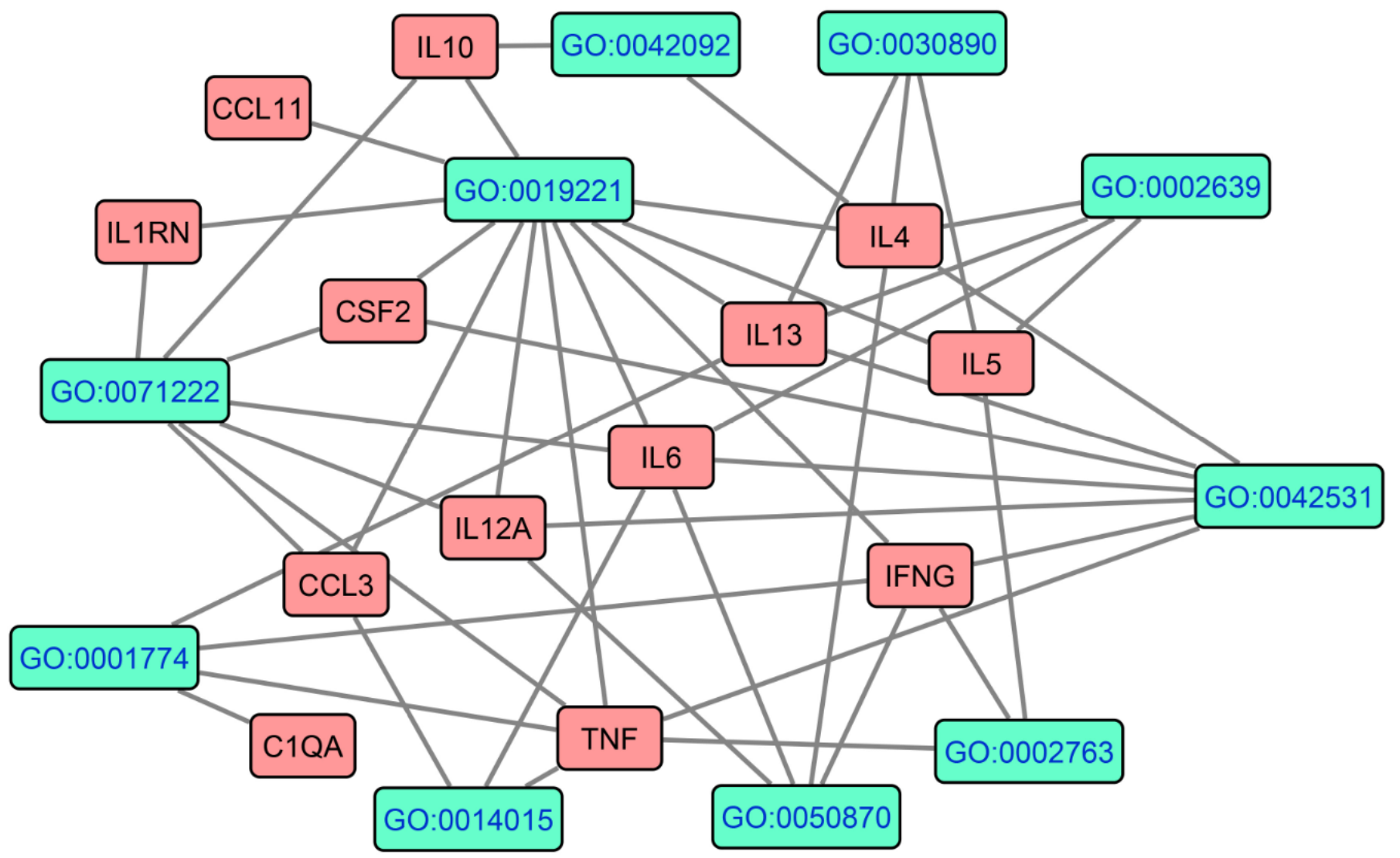

Figure 6. Results of GOnet annotation visualization in FEP/FES depicting the hierarchical structure of GO terms and the upregulated genes. This figure shows the seed protein nodes and the top $10 \mathrm{GO}$ terms (i.e., their most important children).

Figure 7 shows the GOnet annotation analysis results with the GO terms and the four downregulated genes in FEP/FES. The GO term comprised canonical Wnt signaling pathway $\left(\mathrm{GO}: 0060070, \mathrm{pFDR}=3.291 \times 10^{-2}\right)$, entry of bacterium into the host cell (GO:0035635, pFDR $\left.=3.155 \times 10^{-3}\right)$, adherens junctions organization (GO:0034332, $p=3.291 \times 10^{-2}$ ), modulation of chemical synaptic transmission (GO:0050804, pFDR $\left.=1.990 \times 10^{-2}\right)$, synapse assembly $\left(\mathrm{GO}: 0007416\right.$, pFDR $\left.=3.497 \times 10^{-2}\right)$, neuron projection development $(\mathrm{GO}=0031175$, $\left.\mathrm{pFDR}=3.600 \times 10^{-2}\right)$, positive regulation of axonogenesis $\left(\mathrm{GO}: 0050772, \mathrm{pFDR}=3.291 \times 10^{-2}\right)$, positive regulation of neuroblast proliferation (GO:0002052, $\left.\mathrm{pFDR}=9.751 \times 10^{-3}\right)$, cerebral cortex radial glia guided migration $\left(\mathrm{GO}: 0021801\right.$, $\left.\mathrm{pFDR}=9.751 \times 10^{-3}\right)$, and cellular response to indole-3-methanol (GO:0071681, $\left.\mathrm{pFDR}=1.69 \times 10^{-3}\right)$. 


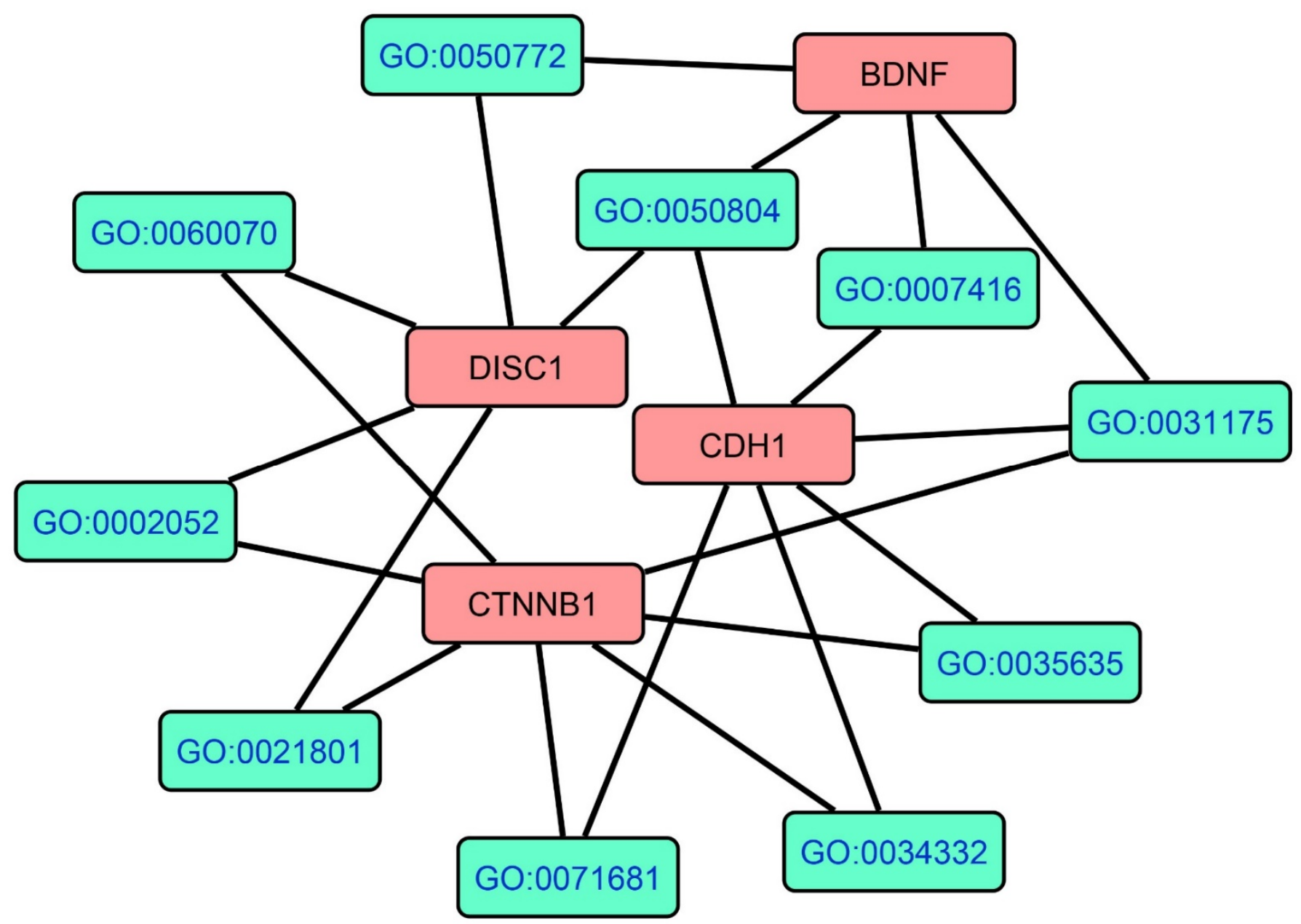

Figure 7. Results of GOnet annotation visualization in FEP/FES depicting the hierarchical structure of GO terms and the downregulated genes. This figure shows the seed protein nodes and the top $10 \mathrm{GO}$ terms (i.e., their most important children).

Figure 8 shows the results of annotation analysis using R package ClusterProfiler and a custom-made GO list comprising parent and child terms exploring response, cellular, or defense response to a variety of stressors, with the aim to differentiate the type of responses, including biotic responses. We observed that the most important over-represented GO terms in the FEP/FES gene list were responses to other organisms, external biotic stimulus, response to lipid, response to bacterium, and response to LPS, whereas there was much less or no evidence for a response to a virus or other biotic (fungal, parasites) or abiotic stimuli.

Consequently, we explored the network of interrelated genes using inBio Discover to delineate which diseases (DOID) are over-represented in the query gene list. Table 3 shows the top nine DOID disease annotations. This table indicates that the proteins involved in FES/FEP are enriched in a number of immune diseases, including immunodeficiency disease and autoimmune disease, and three gastro-intestinal diseases, namely intestinal disease, inflammatory bowel disease, and colitis. ESF Figure S6 shows the extended network and those four of the nine top annotations that were over-represented. The nodes of the extended PPI network involved in immune system and autoimmune disease and inflammatory bowel and intestinal disease are colored in red, orange, blue, and green, respectively. ESF Figure S7 shows all nodes (in red color) which were accumulated in intestinal disease (DOID:5295). ESF Figure S8 shows the results of an annotation analysis for all differentially expressed proteins, using R package ClusterProfiler and the GO list consisting of only leaf children in biological processes. 


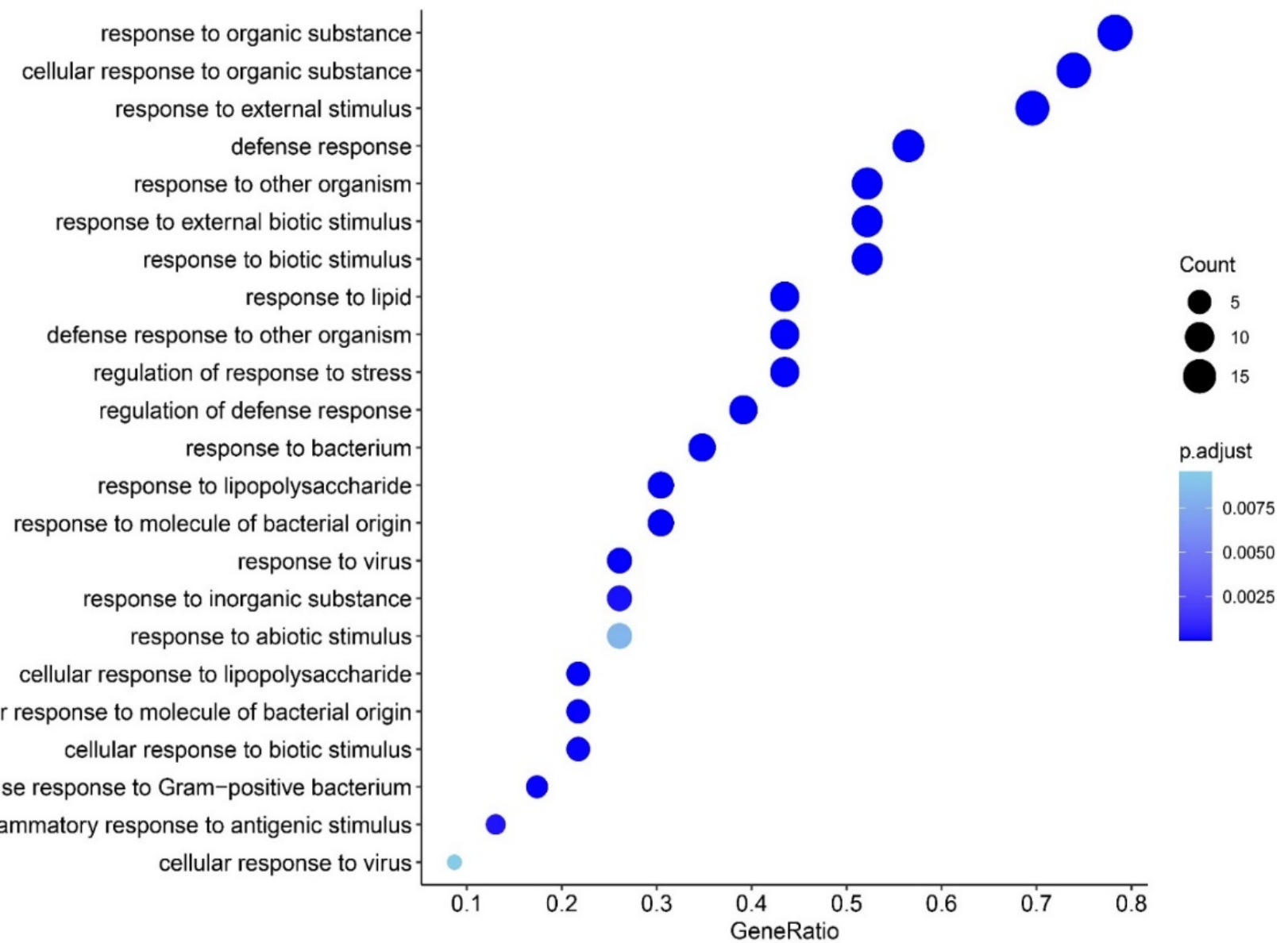

Figure 8. Results of annotation analysis using a custom-made GO list exploring the responses, cellular, or defense responses to a variety of mainly biotic stressors.

Table 3. Results of inBio Discover annotation analysis with the DOID disease annotations classification in first episode psychosis and schizophrenia.

\begin{tabular}{cccccc}
\hline DOID ID & Disease & Size & Overlap & Enrichment & $p$-Value \\
\hline DOID:2914 & immune system disease & $1.9 \mathrm{k}$ & $89 / 246$ & 3.81 & $2.4 \times 10^{-30}$ \\
\hline DOID:612 & primary immunodeficiency syndrome & $1.3 \mathrm{k}$ & $70 / 246$ & 4.28 & $2.9 \times 10^{-26}$ \\
\hline DOID:5295 & intestinal disease & $1.0 \mathrm{k}$ & $61 / 246$ & 4.89 & $9.2 \times 10^{-26}$ \\
\hline DOID:0060032 & $\begin{array}{c}\text { autoimmune disease of the } \\
\text { musculoskeletal system }\end{array}$ & 645 & $48 / 246$ & 6.05 & $4.2 \times 10^{-24}$ \\
\hline DOID:0050589 & inflammatory bowel disease & 306 & $35 / 246$ & 9.30 & $8.7 \times 10^{-24}$ \\
\hline DOID:417 & autoimmune disease & $1.1 \mathrm{k}$ & $58 / 246$ & 4.42 & $3.0 \times 10^{-22}$ \\
\hline DOID:9500 & leukocyte disease & 417 & $38 / 246$ & 7.41 & $3.3 \times 10^{-22}$ \\
\hline DOID:65 & connective tissue disease & $1.8 \mathrm{k}$ & $76 / 246$ & 3.35 & $5.3 \times 10^{-22}$ \\
\hline DOID:0060180 & Colitis & 237 & $30 / 246$ & 10.29 & $8.8 \times 10^{-22}$ \\
\hline
\end{tabular}

\section{Discussion}

\subsection{The PPI Network of FEP/FES}

The first major finding of this study is that we were able to construct zero and firstorder PPI networks of FES/FEP which show high connectivity and some unexpected 
interactions, including the central role of BDNF. We found that the backbone of the FEP network is shaped by six genes (IL6, TNF, IL10, IL4, IFNG, and BDNF) and the backbone of FEP/FES by IL6, TNF, IL10, CCTNB1, CDH1, and BDNF. Moreover, our network analysis revealed two major protein communalities, namely one centered around immuneinflammatory genes and BDNF, and a second cluster around cell-cell junction genes (CTNNB1 and CDH1). Most importantly, BDNF appears to function as a switch between both communalities, as it shows interconnections with immune genes and CTNNB1 and the high-affinity receptor of BDNF, namely neurotrophic tyrosine kinase receptor 2 (NTRK2), which was allocated to the cell-cell junction cluster. Another, smaller, bridge between both communalities is CDH1, which is interconnected with CTNNB1 and with CSF2, IL4, TNF, IL10, and IL6.

Therefore, it appears that an immune response, as observed in FEP/FES, comprises not only IRS and CIRS components [4], but also different neurotrophic (BDNF, NTF4, and NGFR) and cell adhesion (CTNNB1 and CDH1) factors. By inference, the neurotoxic effects of the immune response may be counterbalanced by CIRS (Th-2 and Treg) [7], neuroprotective, and cell-cell adhesion genes. It is tempting to speculate that the participation of neuroprotective and cell-cell adhesion genes in this immune network is another conserved regulatory process protecting against detrimental neuro-immune effects.

\subsection{Trigger Factors in FEP and FEP/FES}

GO annotation and MCODE analysis revealed that the upregulated genes in FEP and the cluster-1 genes in FEP/FES were highly significantly associated with a response to a molecule of bacterial origin and a response to LPS. In fact, a response to LPS was the second most important GO term overexpressed in the upregulated proteins in FEP. Moreover, annotation analysis using a custom-made GO list with possible "responses to ... " or "cellular responses to ... " or a "defense response to ... " showed that the most significant paths enriched in the network were responses to an organic substance (determined as cytokine or lipid), an external stimulus, response to other organisms, or an external biotic stimulus. Further analysis showed that a response to a bacterium and LPS were the most significant paths enriched in the FEP/FES network, whereas a response to a virus was less significant and did not appear in the GO and MCODE enrichment analysis. Moreover, an abiotic stimulus and fungal or parasite stimuli were not significantly enriched.

All in all, it appears that FEP and FEP/FES may be triggered or maintained by a response to LPS of Gram-negative bacteria. These findings corroborate a recent study which reported increased IgA/IgM responses to LPS of Gram-negative bacteria in FES and deficit schizophrenia, and a significant association between these indicants of bacterial load and the G-CoDe (general cognitive impairments) and symptom profiles, especially psychosis $[7,18]$. Such findings may indicate increased bacterial translocation in FES/FEP through leaky gut (increased gut permeability) with deficits in tight and adherens junctions and the vascular barrier, as well [7]. Interestingly, three of the top nine DOID annotations which were overrepresented in the PPI network of FEP/FES comprised intestinal annotations, including intestinal disease, inflammatory bowel disease, and colitis.

\subsection{Upregulated Pathways, Molecular and Cellular Processes in FEP}

The third major finding of this study is that the upregulated genes in FEP were enriched in key pathways and cellular functions that play a key role in immune-inflammatory signaling, namely the receptor signaling pathway via Janus kinases/signal transducer and activator of transcription proteins (JAK-STAT) pathway, the TNFR1-induced NFKB signaling pathway, and TNF- and death receptor signaling. Moreover, STAT3 and STAT6 were prominent nodes in the first order network, with STAT3 occupying a central position. Many cytokines (e.g., IL-2, IL-4, IL-6, IL-10, IL-12, IFN- $\gamma$ ) signal via the JAK-STAT pathway, thereby transactivating Janus kinases leading to translocation of STATs to the nucleus and upregulation of cytokine-modifiable genes [19]. The JAK-STAT pathway plays a key role in inflammation, cell death, cell division, and polarization of T cells; STAT3 is associated 
with autoimmune responses, and STAT6 plays a key role in M2 macrophage activation and Th-2 differentiation with production of IL-4, IL-5, IL-9, and IL-13 [19-21]. Recently, Sharma et al. [22] reported that a subgroup of schizophrenia patients showed increased STAT1 levels.

Our enrichment analyses show that TNF plays an important role in FEP and suggests that TNF-induced IKB kinase (IKK) activation with consequent NFKB translocation to the nucleus is one of the key processes in FEP. Moreover, we found that both NFKB1 and RELA (NFKB p65 unit or transcription factor p65) are the most prominent transcription factors in the FEP network. RELA plays a role in NFKB activation and translocation of the released $\mathrm{NF}_{\kappa} \mathrm{B}$ complex to the nucleoplasm and contributes to DNA binding in the NFKB complex [23]. This NFkB heterodimeric RELA-NFKB1 complex functions as a transcriptional activator and plays a key role in gene expression of multiple cytokines [23]. In schizophrenia, it was shown that increased $N F \kappa B$ activity may contribute to cortical immune activation [24]. In a Japanese population, schizophrenia is associated with variants of the RELA gene and has a significant effect on pre-pulse inhibition [25]. Importantly, this pathway is not only induced by TNF, but also by other cytokines and LPS [26]. Previously, we have reviewed the many neurotoxic effects of increased TNF- $\alpha$ levels in schizophrenia, and especially in deficit schizophrenia [27]. Moreover, the frequency of the TNF2(A) allele, which affects plasma TNF levels, is significantly increased in schizophrenia and TNF2 homozygotes are detected in schizophrenia only [6].

\subsection{Downregulated Pathways, Molecular and Cellular Processes in FEP}

The fourth major finding is that the downregulated genes were enriched in the receptor protein tyrosine kinase (RTK) and neurotrophin/Trk receptor signaling pathways, cellular component morphogenesis, and production of miRNAs involved in gene silencing. RTK is a family of high-affinity cell surface receptors, including Trk, which is activated by neurotrophins such as BDNF [28]. Interestingly, RTKs regulate the threshold for macrophage activation, thereby promoting homeostasis and protecting tissues from inflammatory damage [29]. BDNF/Trk signaling contributes to axonal growth, axonal guidance, plasticity, dendritic arborization, synapse structure and formation and connections, neurogenesis, differentiation of new neurons and synapses, and axonal and dendritic sprouting [30]. Moreover, BDNF may have anti-inflammatory and anti-apoptopic effects via modulation of MyD88/NFKB and PI3K/AKT-signaling pathways [31]. Following bacterial infection, BDNF pretreatment reduces the expression of TNF- $\alpha$, IL-16, IL- $1 \beta$, and the NFKB pathways, and increases IL-10 and Trk expression [31]. LPS-associated inflammation alters BDNF/TrkB signaling in the hippocampus, nucleus accumbens, and prefrontal cortex in association with the onset of depressive behaviors [32]. A recent meta-analysis showed that schizophrenia is associated with reduced BDNF with a medium effect size (Hedges $\mathrm{g}=-0.458, p<0.004)$, and that these effects are not influenced by the drug state of the patients [33]. Moreover, the interaction between BDNF and NTRK2 gene polymorphisms may increase susceptibility to paranoid schizophrenia [34].

We found that the downregulated DISC1 gene is enriched in various GO biological terms indicating neurogenesis, axonogenesis, and axon extension. DISC1 is now established as a risk factor for schizophrenia and other major psychiatric illness and is involved in aspects of adult progenitor proliferation, neurogenesis, neurite outgrowth, cytoskeletal modulation, signal transduction, and CTNNB1 abundance [35,36]. It is interesting to note that inflammatory signaling via TLR3 is accompanied by impairments in dendritic spine and growth via effects on MYD88 and, consequently, DISC1 expression [37].

Another highly significant GO path enriched in the downregulated network was the "production of miRNAs involved in gene silencing by miRNA", which may, at least in part, be ascribed to downregulation of DROSHA, which is a ribonuclease (RNase) III family enzyme and plays a key role in miRNA maturation [38]. In mammals, the miRNA network comprises 5000-10,000 miRNAs which regulate the expression of $60 \%$ of the protein-coding genes through translational silencing and mRNA destabilization [39,40]. Importantly, 
miRNA regulate the adaptive and innate immune response and act as fine-tuning regulators, preventing an overzealous inflammatory response and thereby maintaining homeostasis [40]. Many of the miRNAs which are associated with schizophrenia phenotypes [41,42] display immune regulatory effects. For example, miR-9 exerts a negative feedback on NFKB and is dysregulated in neural progenitor cells of schizophrenia patients [43]; miR-132 inhibits inflammation signaling (via acetylcholine, STAT3, and NFKB) and is dysregulated in schizophrenia [44]; miR-146 inhibits inflammatory responses and is downregulated in monocytes of postpartum psychosis patients [45]; and miR-149 inhibits LPS-induced inflammation (via STAT3, NFKB, TNF, IL-6) and is a candidate biomarker of psychiatric disease including bipolar disorders [46].

\subsection{Pathways, Molecular and Cellular Processes in FEP/FES}

The enrichment and annotation analysis revealed other important drug targets in FEP/FES. Firstly, we found that a neuroinflammatory response was enriched in the seed gene FEP/FES list, whilst MCODE showed that a cytokine/chemokine complex of IFN- $\gamma$, IL-6, IL-12A, CCL3, IL-4, and IL-13 was strongly associated with microglial cell activation and tyrosine phosphorylation of STAT proteins. These results extend the findings that schizophrenia is accompanied by microglial activation [47]. Moreover, the upregulated genes in FEP/FES were enriched in "the positive regulation of gliogenesis". In adulthood, gliogenesis is maintained to renew oligodendrocytes; however, following inflammatory disease and injuries, gliogenesis becomes more active (reactive astroytosis or astrogliosis) and may have negative consequences, thereby contributing to immune-inflammatory responses and altering the balance between neurogenesis and gliogenesis [48].

Secondly, WikiPathway and PANTHER enrichment analysis revealed that the upregulated genes were strongly associated with the TLR signaling (especially TLR4) and tolerance pathways. These findings extend those of previous publications indicating activation of the TLR4 proinflammatory pathway in schizophrenia [49].

Third, GO annotation analysis revealed that the cluster 2 genes are enriched in the Wnt/catenin pathway and cell-cell junction organization. Moreover, different combinations of the downregulated genes were associated with the Wnt/catenin pathway (DISC1 and CTNNB1), adherens junctions organization (CDH1 and CTNNB1), synapse assembly (CDH1 and BDNF), neuron projection development (BDNF, CTNNB1 and CDH1), neuroblast proliferation (DISC1 and CTNNB1), cerebral cortex radial glia guided migration (DISC1 and CTNNB1), positive regulation of axonogenesis (BDNF and DISC1), and modulation of chemical synaptic transmission (BDNF, CDH1 and DISC1).

CTNNB1 is a component of the Wnt/ $\beta$-catenin signaling pathway and the E-cadherincatenin adhesion complex, which play a key role in epithelial integrity and tissue architecture maintenance $[50,51]$. The $\mathrm{Wnt} /$ catenin pathway is strongly involved in neurogenesis, axonal spreading and branching, connectivity between pre- and post-synaptic neuronal regions, regulation of synaptic functions and modeling of synaptic structures, modulation of excitatory synaptic transmission, LTP, and post-synaptic protein assembly [52]. The Wnt/ $\beta$-catenin signaling pathway also regulates immune-inflammatory responses and T-cell-inflammation [53-55]. Inflammatory responses, due to infections with pathogenic bacteria, may affect the Wnt/ $\beta$-catenin signaling pathway [55] and the E-cadherin-catenin adhesion complex [56]. For example, in inflammatory bowel disease, impairments in the latter complex are affected by the inflammatory milieu and may cause dysregulations of the actin cytoskeleton leading to aberrations in intracellular signaling and transcriptional regulation [57]. Moreover, the Wnt/catenin pathway may regulate BDNF expression while these two pathways may have common effector actions [58], and BDNF polymorphisms are associated with changes in the Wnt/ $\beta$-catenin pathway [59]. In hippocampal neurons, BDNF-disruption of cadherin- $\beta$-catenin complexes is associated with increased synapse density [60].

Disorders in the Wnt/catenin pathway were previously described in FES and schizophrenia $[7,61,62]$ and alterations in E-cadherin and beta-catenin levels in FES are strongly associated 
with increased bacterial translocation [7]. This more generalized disorder in paracellular and cell-cell junctions in FEP/FES may, at least in part, be related with the increased frequency of the Hp2 allele and the Hp2.2 genotype (prehaptoglobin-2 or zonulin) [63] and increased zonulin levels [64]. Moreover, mutations in the CTNNB1 gene (c.1943 $A>G)$ are associated with schizophrenia [65], whilst CTNNB1 KO mice display anxiety behaviors and CTNNB1 $\mathrm{KO}$ in paraventricular interneurons accompanied by impairments in social interactions, repetitive behaviors, and object recognition [66]. Association, candidate gene, and genomewide association studies show that cadherins may be involved in the pathophysiology of schizophrenia $[67,68]$.

Fourth, exploration of transcriptional regulation showed that SP1, NFkB1, and RELA were the most prominent transcription factors in the FEP/FES network. SP1 or specificity protein 1 (or transcription factor Sp1) is a ubiquitously expressed transcription factor, which regulates the expression of a variety of house-keeping and tissue-restricted genes frequently involved in immune responses, response to DNA damage, and apoptosis [69]. This explains that SP1 is associated with the pathophysiology of some neurodegenerative and neuroinflammatory disorders, including Alzheimer's and Huntington's disease and multiple sclerosis [69]. Interestingly, neurons have a decreased capacity of activating $\mathrm{NF} \kappa \mathrm{B}$, but $\mathrm{\kappa B}$ cis elements may bind to SP1 [70] and SP1 interacts with RELA to form a complex [71]. In cortical neurons, SP1 is an oxidatively-induced transcription factor which regulates neuronal survival [72]. In Huntington's disease, pathogenic SP1 cascades cause repression of neuronal genes [73]. Interestingly, both NFKB and SP1 modulate antimicrobial activity against Gram-negative bacteria [74].

Fifth, biological GO term classifications showed that complement factors were enriched not only in microglial activation and humoral immune responses, but also in synapse pruning and organization. The involvement of complement in FEP/FES agrees with previous findings showing increased plasma C3C and C4 and CSF and brain C4 complement factors in schizophrenia $[2,75,76]$. Moreover, increased C1qA, C3, and C4 transcripts were reported to be associated with microglial activation in the midbrain of schizophrenia patients [77]. It should be added that FES is accompanied by increased formation of the IgA C1qA CIC, which may have detrimental effects in its own right [7]. Nevertheless, the complement pathways established in FEP/FES are not a key component of the interactome and, therefore, should be considered as secondary phenomena. In addition, also PON1 was not a key component of the interactome and showed only a few interactions. Other CIRS components could not be included, such as natural IgM responses to oxidatively specific epitopes [7]. Both PON1 and natural IgM are first line innate immune defenses against bacterial infections and display strong anti-inflammatory and antioxidant properties, explaining that impairments in both systems contribute to FEP/FES [7].

\subsection{Conclusions}

Figure 9 shows a summary of the enrichment and annotation analysis reported in our study. All in all, the analyses suggest that increased bacterial translocation, in particular that of Gram-negative bacteria, is the most probable trigger and maintaining factor of FEP and FEP/FES, causing an immune-inflammatory milieu with involvement of TNF, NFKB/RELA, SP1, and JAK-STAT signaling, including tyrosine phosphorylation of STAT proteins, and death receptor and TLR4 signaling. A specific cytokine/chemokine complex consisting of IFN- $\gamma$, IL-6, IL-12A, CCL3, IL-4, and IL-13 is strongly associated with microglial activation and neuroinflammation, and this upregulated immune network additionally positively regulates gliogenesis. FEP/FES is also accompanied by lowered immune regulation and thus protection against an overzealous inflammatory process due to dysfunctional miRNA maturation, and deficits in neurotrophin/Trk, RTK and Wnt/catenin signaling. 
Response to external stimulus

Response to other organism

Response to external biotic

stimulus

Response to bacterium Response to molecule of bacterial origin

Response to LPS

\section{Upregulated network}

Inflammatory response

Receptor signaling pathway via JAK-STAT

Regulation of tyrosine phosphorylation of STAT protein

Toll-like receptor signaling pathway

TNF signaling

TNFR1-induced NFkappaB signaling pathway

I-кB/NF $\mathrm{B}$ signaling

NFкB/RELA transcription

Death receptor signaling

Extrinsic apoptotic signaling pathway

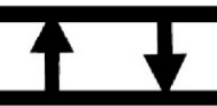

Downregulated network

Beta-catenin TCF complex

Cell-cell junction organization

Adherens junction organization

Wnt/catenin signaling pathway

Neurotrophin/TRK receptor signaling pathway

Transmembrane receptor protein tyrosine kinase

signaling pathway

Cellular component morphogenesis

Production of miRNAs involved in gene silencing by

miRNA
Microglial cell activation

Neuroinflammation

Positive regulation of gliogenesis
Neuron projection development Positive regulation of axonogenesis Positive regulation of neuroblast proliferation

Cerebral cortex radial glia guided migration

Regulation of axon extension

Cerebral cortex radially oriented cell

migration

Synapse assembly

Synapse pruning

Modulation of chemical synaptic

transmission

Memory

Learning and behavior

Figure 9. Summary of the findings of the enrichment/annotation analysis using upregulated and downregulated genes in first episode psychosis and schizophrenia.

By inference, individuals with reduced CIRS [4], including miRNA maturation and deficits in neurotrophin/Trk, RTK, and Wnt/catenin signaling, neuroprotection (including neurotrophin/Trk and Wnt/catenin signaling, lowered DISC1 expression, and interactions between reduced BDNF, CDH1, CTNNB, and DISC1 may be at an increased risk to develop FEP and FES as a consequence of an immune response following bacterial infections and the ensuing neuro-immune toxicity. The latter may cause a multitude of neuronal dysfunctions and cognitive impairments and schizophrenia behaviors [7], as shown in Figure 9.

Interestingly, almost all pathways or molecular patterns enriched in the interactome of FEP/FES are directly (NFKB/RELA, TLRs, TNF, adherens junctions and cell-cell junctions, complement activation with C1QA CIC formation, neurotrophin/Trk pathway, Wnt signaling, microglial activation, gliogenesis, neurotoxicity) or indirectly (JAK-STAT, DISC1, SP1) affected by LPS. As such, the increased LPS levels in FES may maintain peripheral and central immune activation resulting in neurotoxic effects on central neuronal circuitry, neurogenesis, and synapse functions [7]. Disorders in cell-cell junction organization may contribute to the maintenance of increased bacterial translocation and activation of complement cascades with increased IgA C1QA CIC formation, which may further fuel the immune response [7]. It should be added that LPS-induced maternal immune activation may have increased the vulnerability to such immune hits by inducing neurodevelopmental disorders with sensitized immune-inflammatory pathways (including in TLR4 and inflammasome) and lowered neuroprotection [78,79].

Future research in FEP should examine the microbiome, gut dysbiosis, and consequent bacterial translocation due to leaky gut as well as alterations in the microbiota-gut-brain axis [18], which may ultimately activate or dysregulate the many pathways discussed in the current review. In addition, it would be most informative to examine differences in the gut-brain axis between FEP, deficit schizophrenia, and other major psychiatric and psychosomatic disorders. There is some evidence that increased leaky gut and bacterial translocation and their impact on neuro-immune pathways may be a transdiagnostic phenomenon [80] which is detected in affective disorders [81] and Myalgic Encephalomyeli- 
tis [82]. Future research should examine the effects of new or repurposing drugs and natural anti-inflammatory and antioxidant compounds on the gut-brain axis and intracellular pathways in FEP (see Figure 9). For example, one could aim to attenuate the primary bacterial translocation in FEP by using minocycline, which has, additionally, anti-inflammatory and antioxidant capacities [83]. One could also aim to target NFkB using specific kinase inhibitors with or without natural NFKB inhibitors, such as curcuma [84]. However, a novel approach to treating FEP and, thus, preventing schizophrenia, its worsening course, and the onset of deficit syndrome appears to require a highly complex approach, as deficiencies in the CIRS and neurotrophic factors appear to be critical. As such, combination therapies with immunotherapies (including intravenous immunoglobulins, which have some efficacy in schizophrenia in case reports [85]) and neurotrophic factors [84] appear to be warranted.

Supplementary Materials: The following are available online at https:/ / www.mdpi.com/article/ 10.3390/cells10112929/s1, Figure S1: Heatmap (top-10) of enriched GO cellular component terms accumulated in the differently expressed proteins in first episode psychosis and schizophrenia., Figure S2: Heatmap (top-10) of enriched Reactome terms over-represented in the differently expressed proteins in first episode psychosis and schizophrenia, Figure S3: Heatmap (top-10) of enriched Panther Pathways that were over-represented in the differently expressed proteins in first episode psychosis and schizophrenia. Figure S4: Heatmap (top-10) of enriched WikiPathways that were over-represented in the differently expressed proteins in first episode psychosis and schizophrenia. Figure S5: Protein-protein interaction network (built with OmicsNet and IntAct) of first episode psychosis and schizophrenia. The top-3 transcriptional factors are shown as blue spots (SP1, NFKB1, and RELA). Proteins in green and bundles in pink. Figure S6. Protein-protein interaction network (built with inBio Discover) of differently expressed proteins in first episode psychosis and schizophrenia. Shown are 4 top annotations that are over-represented in the gene list, namely: red color: immune system disease (DOID:2914); blue color: inflammatory bowel disease (DOID:0050589); green color: intestinal disease (DOID:5295); yellow color: autoimmune disease (DOID:417) Figure S7: Differently expressed proteins in the extended protein-protein interaction network that accumulated in intestinal disease (DOID:5295). Figure S8. GO functional enrichment analysis of all differently expressed proteins in first episode psychosis and schizophrenia using $\mathrm{R}$ package ClusterProfiler. Only annotated $\mathrm{GO}$ term leaves are shown in this figure. The $\mathrm{x}$-axis shows the gene ratio and the $y$-axis the annotated GO biological terms. The size of the dots is proportional to the gene number; $p$-values of all GO terms are colored as indicated in the figure.

Author Contributions: Conceptualization, M.M., formal analysis, M.M., K.P., A.S., writing-original draft preparation, M.M., writing—review and editing, K.P., A.S., B.K., C.N.; visualization, M.M., K.P., funding acquisition, B.K. All authors have read and agreed to the published version of the manuscript.

Funding: This research was funded by the Asahi Glass Foundation, Chulalongkorn University Centenary Academic Development Project.

Institutional Review Board Statement: Not applicable. This study is a secondary data analysis on existing data (which were openly available to the public before the initiation of the study) using open, deidentified and non-coded datasets and, therefore, this is non-human subjects research, which is not subject to IRB approval.

Informed Consent Statement: Not applicable.

Data Availability Statement: Data are openly available to the public in [7-11,16].

Conflicts of Interest: The authors declare no conflict of interest.

\section{References}

1. Smith, R.; Maes, M. The macrophage-T-lymphocyte theory of schizophrenia: Additional evidence. Med. Hypotheses 1995, 45, 135-141. [CrossRef]

2. Maes, M.; Delange, J.; Ranjan, R.; Meltzer, H.Y.; Desnyder, R.; Cooremans, W.; Scharpé, S. Acute phase proteins in schizophrenia, mania and major depression: Modulation by psychotropic drugs. Psychiatry Res. 1997, 66, 1-11. [CrossRef]

3. Maes, M.; Meltzer, H.Y.; Bosmans, E. Immune-inflammatory markers in schizophrenia: Comparison to normal controls and effects of clozapine. Acta Psychiatr. Scand. 1994, 89, 346-351. [CrossRef] 
4. Roomruangwong, C.; Noto, C.; Kanchanatawan, B.; Anderson, G.; Kubera, M.; Carvalho, A.F.; Maes, M. The Role of Aberrations in the Immune-Inflammatory Response System (IRS) and the Compensatory Immune-Regulatory Reflex System (CIRS) in Different Phenotypes of Schizophrenia: The IRS-CIRS Theory of Schizophrenia. Mol. Neurobiol. 2020, 57, 778-797. [CrossRef]

5. Comer, A.L.; Carrier, M.; Tremblay, M.-Ė; Cruz-Martín, A. The Inflamed Brain in Schizophrenia: The Convergence of Genetic and Environmental Risk Factors That Lead to Uncontrolled Neuroinflammation. Front. Cell. Neurosci. 2020, 14. [CrossRef] [PubMed]

6. Boin, F.; Zanardini, R.; Pioli, R.; Altamura, C.A.; Maes, M.; Gennarelli, M. Association between -G308A tumor necrosis factor alpha gene polymorphism and schizophrenia. Mol. Psychiatry 2001, 6, 79-82. [CrossRef]

7. Maes, M.; Vojdani, A.; Sirivichayakul, S.; Barbosa, D.S.; Kanchanatawan, B. Inflammatory and Oxidative Pathways Are New Drug Targets in Multiple Episode Schizophrenia and Leaky Gut, Klebsiella pneumoniae, and C1q Immune Complexes Are Additional Drug Targets in First Episode Schizophrenia. Mol. Neurobiol. 2021, 58, 1-16. [CrossRef] [PubMed]

8. Noto, M.N.; Maes, M.; Nunes, S.O.V.; Ota, V.K.; Rossaneis, A.C.; Verri, W.A., Jr.; Cordeiro, Q.; Belangero, S.I.; Gadelha, A.; Bressan, R.A.; et al. Activation of the immune-inflammatory response system and the compensatory immune-regulatory system in antipsychotic naive first episode psychosis. Eur. Neuropsychopharmacol. 2019, 29, 416-431. [CrossRef] [PubMed]

9. Noto, C.; Ota, V.K.; Santoro, M.L.; Gouvea, E.S.; Silva, P.N.; Spindola, L.; Cordeiro, Q.; Bressan, R.; Gadelha, A.; Brietzke, E.; et al. Depression, Cytokine, and Cytokine by Treatment Interactions Modulate Gene Expression in Antipsychotic Naïve First Episode Psychosis. Mol. Neurobiol. 2016, 53, 5701-5709. [CrossRef] [PubMed]

10. Noto, M.N.; Maes, M.; Nunes, S.O.V.; Ota, V.K.; Cavalcante, D.; Oliveira, G.; Rossaneis, A.C.; Verri, W.A.; Cordeiro, Q.; Belangero, S.I.; et al. BDNF in antipsychotic naive first episode psychosis: Effects of risperidone and the immune-inflammatory response system. J. Psychiatr. Res. 2021, 141, 206-213. [CrossRef] [PubMed]

11. Maes, M.; Sirivichayakul, S.; Matsumoto, A.K.; Michelin, A.P.; Semeão, L.D.O.; Pedrão, J.V.D.L.; Moreira, E.G.; Barbosa, D.S.; Carvalho, A.F.; Solmi, M.; et al. Lowered Antioxidant Defenses and Increased Oxidative Toxicity Are Hallmarks of Deficit Schizophrenia: A Nomothetic Network Psychiatry Approach. Mol. Neurobiol. 2020, 57, 4578-4597. [CrossRef] [PubMed]

12. Jindal, R.D.; Pillai, A.K.; Mahadik, S.P.; Eklund, K.; Montrose, D.M.; Keshavan, M.S. Decreased BDNF in patients with antipsychotic naïve first episode schizophrenia. Schizophr. Res. 2010, 119, 47-51. [CrossRef] [PubMed]

13. Maes, M.; Kanchanatawan, B. In (deficit) schizophrenia, a general cognitive decline partly mediates the effects of neuro-immune and neuro-oxidative toxicity on the symptomatome and quality of life. CNS Spectrums 2021, 12, 1-10. [CrossRef]

14. Chen, S.J.; Liao, D.L.; Chen, C.H.; Wang, T.Y.; Chen, K.C. Construction and Analysis of Protein-Protein Interaction Network of Heroin Use Disorder. Sci Rep 2019, 9, 4980. [CrossRef]

15. Brinholi, F.F.; Noto, C.; Maes, M.; Bonifácio, K.L.; Brietzke, E.; Ota, V.K.; Gadelha, A.; Cordeiro, Q.; Belangero, S.; Bressan, R.; et al. Lowered paraoxonase 1 (PON1) activity is associated with increased cytokine levels in drug naïve first episode psychosis. Schizophr. Res. 2015, 166, 225-230. [CrossRef] [PubMed]

16. Noto, C.; Ota, V.K.; Gadelha, A.; Noto, M.N.; Barbosa, D.S.; Bonifácio, K.L.; Nunes, S.O.; Cordeiro, Q.; Belangero, S.; Bressan, R.; et al. Oxidative stress in drug naïve first episode psychosis and antioxidant effects of risperidone. J. Psychiatr. Res. 2015, 68, 210-216. [CrossRef]

17. Zhou, Y.; Zhou, B.; Pache, L.; Chang, M.; Khodabakhshi, A.H.; Tanaseichuk, O.; Benner, C.; Chanda, S.K. Metascape provides a biologist-oriented resource for the analysis of systems-level datasets. Nat. Commun. 2019, 10, 1-10. [CrossRef] [PubMed]

18. Maes, M.; Kanchanatawan, B.; Sirivichayakul, S.; Carvalho, A.F. In Schizophrenia, Increased Plasma IgM/IgA Responses to Gut Commensal Bacteria Are Associated with Negative Symptoms, Neurocognitive Impairments, and the Deficit Phenotype. Neurotox. Res. 2018, 35, 684-698. [CrossRef] [PubMed]

19. Morris, R.; Kershaw, N.J.; Babon, J.J. The molecular details of cytokine signaling via the JAK/STAT pathway. Protein Sci. 2018, 27, 1984-2009. [CrossRef]

20. Murray, P.J. The JAK-STAT Signaling Pathway: Input and Output Integration. J. Immunol. 2007, 178, 2623-2629. [CrossRef]

21. Gong, M.; Zhuo, X.; Ma, A. STAT6 Upregulation Promotes M2 Macrophage Polarization to Suppress Atherosclerosis. Med. Sci. Monit. Basic Res. 2017, 23, 240-249. [CrossRef]

22. Sharma, R.P.; Rosen, C.; Melbourne, J.K.; Feiner, B.; Chase, K.A. Activated Phosphorylated STAT1 Levels as a Biologically Relevant Immune Signal in Schizophrenia. Neuroimmunomodulation 2016, 23, 224-229. [CrossRef] [PubMed]

23. UniProtB. UniProtKB-Q04206 (TF65_HUMAN). RELA—Transcription Factor p65—Homo Sapiens (Human)—RELA Gene \& Protein. Available online: Uniprot.org (accessed on 23 July 2021).

24. Volk, D.W.; Moroco, A.E.; Roman, K.M.; Edelson, J.R.; Lewis, D.A. The Role of the Nuclear Factor- $k$ B Transcriptional Complex in Cortical Immune Activation in Schizophrenia. Biol. Psychiatry 2019, 85, 25-34. [CrossRef]

25. Hashimoto, R.; Ohi, K.; Yasuda, Y.; Fukumoto, M.; Yamamori, H.; Takahashi, H.; Iwase, M.; Okochi, T.; Kazui, H.; Saitoh, O.; et al. Variants of the RELA Gene are Associated with Schizophrenia and their Startle Responses. Neuropsychopharmacology 2011, 36, 1921-1931. [CrossRef] [PubMed]

26. Wajant, H.; Scheurich, P. TNFR1-induced activation of the classical NF-kB pathway. FEBS J. 2011, 278, 862-876. [CrossRef]

27. Maes, M.; Sirivichayakul, S.; Matsumoto, A.K.; Maes, A.; Michelin, A.P.; de Oliveira Semeão, L.; de Lima Pedrão, J.V.; Moreira, E.G.; Barbosa, D.S.; Geffard, M.; et al. Increased Levels of Plasma Tumor Necrosis Factor- $\alpha$ Mediate Schizophrenia Symptom Dimensions and Neurocognitive Impairments and Are Inversely Associated with Natural IgM Directed to Malondialdehyde and Paraoxonase 1 Activity. Mol. Neurobiol. 2020, 57, 2333-2345. [CrossRef] [PubMed] 
28. Leopold, A.; Chernov, K.G.; Shemetov, A.A.; Verkhusha, V.V. Neurotrophin receptor tyrosine kinases regulated with near-infrared light. Nat. Commun. 2019, 10, 1-13. [CrossRef] [PubMed]

29. Correll, P.H.; Morrison, A.C.; Lutz, M.A. Receptor tyrosine kinases and the regulation of macrophage activation. J. Leukoc. Biol. 2004, 75, 731-737. [CrossRef]

30. Creative Diagnostics. Neurotrophin Signaling Pathway. Neurotrophin Signaling Pathway-Creative Diagnostics. Available online: Crea-tive-diagnostics.com (accessed on 18 July 2021).

31. Xu, D.; Lian, D.; Wu, J.; Liu, Y.; Zhu, M.; Sun, J.; He, D.; Li, L. Brain-derived neurotrophic factor reduces inflammation and hippocampal apoptosis in experimental Streptococcus pneumoniae meningitis. J. Neuroinflammation 2017, 14, 1-13. [CrossRef]

32. Zhang, J.-C.; Yao, W.; Hashimoto, K. Brain-derived Neurotrophic Factor (BDNF)-TrkB Signaling in Inflammation-related Depression and Potential Therapeutic Targets. Curr. Neuropharmacol. 2016, 14, 721-731. [CrossRef] [PubMed]

33. Green, M.J.; Matheson, S.L.; Shepherd, A.; Weickert, C.S.; Carr, V.J. Brain-derived neurotrophic factor levels in schizophrenia: A systematic review with meta-analysis. Mol. Psychiatry 2011, 16, 960-972. [CrossRef]

34. Lin, Z.; Su, Y.; Zhang, C.; Xing, M.; Ding, W.; Liao, L.; Guan, Y.; Li, Z.; Cui, N. The Interaction of BDNF and NTRK2 Gene Increases the Susceptibility of Paranoid Schizophrenia. PLOS ONE 2013, 8, e74264. [CrossRef]

35. Hennah, W.; Thomson, P.; Peltonen, L.; Porteous, D. Genes and Schizophrenia: Beyond Schizophrenia: The Role of DISC1 in Major Mental Illness. Schizophr. Bull. 2006, 32, 409-416. [CrossRef] [PubMed]

36. UniProt. UniProtKB—Q9NRI5 (DISC1_HUMAN). DISC1—Disrupted in Schizophrenia 1 Protein-Homo Sapiens (Human)— DISC1 Gene \& Protein. Available online: Uniprot.org (accessed on 18 July 2021).

37. Chen, C.; Liu, H.-Y.; Hsueh, Y. TLR 3 downregulates expression of schizophrenia gene Disc1 via MYD 88 to control neuronal morphology. EMBO Rep. 2017, 18, 169-183. [CrossRef] [PubMed]

38. Aharoni, R.; Tobi, D. Dynamical comparison between Drosha and Dicer reveals functional motion similarities and dissimilarities. PLoS ONE 2019, 14, e0226147. [CrossRef]

39. Catalanotto, C.; Cogoni, C.; Zardo, G. MicroRNA in Control of Gene Expression: An Overview of Nuclear Functions. Int. J. Mol. Sci. 2016, 17, 1712. [CrossRef] [PubMed]

40. Tahamtan, A.; Teymoori-Rad, M.; Nakstad, B.; Salimi, V. Anti-Inflammatory MicroRNAs and Their Potential for Inflammatory Diseases Treatment. Front. Immunol. 2018, 9, 1377. [CrossRef]

41. Caputo, V.; Ciolfi, A.; Macri, S.; Pizzuti, A. The emerging role of MicroRNA in schizophrenia. CNS Neurol. Disord.-Drug Targets 2015, 14, 208-221. [CrossRef]

42. Cao, T.; Zhen, X.-C. Dysregulation of miRNA and its potential therapeutic application in schizophrenia. CNS Neurosci. Ther. 2018, 24, 586-597. [CrossRef]

43. Topol, A.; Zhu, S.; Hartley, B.J.; English, J.; Hauberg, M.E.; Tran, N.; Rittenhouse, C.A.; Simone, A.; Ruderfer, D.; Johnson, J.; et al. Dysregulation of miRNA-9 in a Subset of Schizophrenia Patient-Derived Neural Progenitor Cells. Cell Rep. 2016, 15, 1024-1036. [CrossRef]

44. Miller, B.H.; Zeier, Z.; Xi, L.; Lanz, T.; Deng, S.; Strathmann, J.; Willoughby, D.; Kenny, P.J.; Elsworth, J.D.; Lawrence, M.S.; et al. MicroRNA-132 dysregulation in schizophrenia has implications for both neurodevelopment and adult brain function. Proc. Natl. Acad. Sci. USA 2012, 109, 3125-3130. [CrossRef] [PubMed]

45. Weigelt, K.; Bergink, V.; Burgerhout, K.M.; Pescatori, M.; Wijkhuijs, A.; Drexhage, H.A. Down-regulation of inflammationprotective microRNAs 146a and 212 in monocytes of patients with postpartum psychosis. Brain, Behav. Immun. 2013, 29, 147-155. [CrossRef] [PubMed]

46. Choi, J.L.; Kao, P.F.; Itriago, E.; Zhan, Y.; Kozubek, J.A.; Hoss, A.G.; Banigan, M.G.; Vanderburg, C.R.; Rezvani, A.H.; Latourelle, J.C.; et al. miR-149 and miR-29c as candidates for bipolar disorder biomarkers. Am. J. Med Genet. Part B Neuropsychiatr. Genet. 2017, 174, 315-323. [CrossRef]

47. van Rees, G.F. The Involvement of Microglial Activation in Schizophrenia; Queens College, University of Cambridge: Cambridge, UK, 2017.

48. Rusznák, Z.; Henskens, W.; Schofield, E.; Kim, W.S.; Fu, Y. Adult Neurogenesis and Gliogenesis: Possible Mechanisms for Neurorestoration. Exp. Neurobiol. 2016, 25, 103-112. [CrossRef]

49. García-Bueno, B.; Gassó, P.; MacDowell, K.S.; Callado, L.F.; Mas, S.; Bernardo, M.; Lafuente, A.; Meana, J.J.; Leza, J.C. Evidence of activation of the Toll-like receptor-4 proinflammatory pathway in patients with schizophrenia. J. Psychiatry Neurosci. 2016, 41, E46-E55. [CrossRef] [PubMed]

50. Tian, X.; Liu, Z.; Niu, B.; Zhang, J.; Tan, T.K.; Lee, S.R.; Zhao, Y.; Harris, D.C.H.; Zheng, G. E-Cadherin/ $\beta$-Catenin Complex and the Epithelial Barrier. J. Biomed. Biotechnol. 2011, 2011, 567305. [CrossRef]

51. van Roy, F.; Berx, G. The cell-cell adhesion molecule E-cadherin. Cell Mol. Life Sci. 2008, 65, 3756-3788. [CrossRef] [PubMed]

52. Oliva, C.A.; Vargas, J.Y.; Inestrosa, N.C. Wnts in adult brain: From synaptic plasticity to cognitive deficiencies. Front. Cell. Neurosci. 2013, 7, 224. [CrossRef] [PubMed]

53. Jridi, I.; Canté-Barrett, K.; Pike-Overzet, K.; Staal, F.J.T. Inflammation and Wnt Signaling: Target for Immunomodulatory Therapy? Front. Cell Dev. Biol. 2021, 8, 615131. [CrossRef]

54. Li, X.; Xiang, Y.; Li, F.; Yin, C.; Li, B.; Ke, X. WNT / $\beta$-Catenin Signaling Pathway Regulating T Cell-Inflammation in the Tumor Microenvironment. Front. Immunol. 2019, 10, 2293. [CrossRef] 
55. Silva-García, O.; Valdez-Alarcón, J.J.; Baizabal-Aguirre, V.M. The Wnt/ $\beta$-Catenin Signaling Pathway Controls the Inflammatory Response in Infections Caused by Pathogenic Bacteria. Mediat. Inflamm. 2014, 2014, 310183. [CrossRef] [PubMed]

56. Devaux, C.A.; Mezouar, S.; Mege, J.-L. The E-Cadherin Cleavage Associated to Pathogenic Bacteria Infections Can Favor Bacterial Invasion and Transmigration, Dysregulation of the Immune Response and Cancer Induction in Humans. Front. Microbiol. 2019, 10, 2598. [CrossRef] [PubMed]

57. Mehta, S.; Nijhuis, A.; Kumagai, T.; Lindsay, J.; Silver, A. Defects in the adherens junction complex (E-cadherin/ $\beta$-catenin) in inflammatory bowel disease. Cell Tissue Res. 2015, 360, 749-760. [CrossRef]

58. Yi, H.; Hu, J.; Qian, J.; Hackam, A.S. Expression of brain-derived neurotrophic factor is regulated by the Wnt signaling pathway. NeuroReport 2012, 23, 189-194. [CrossRef]

59. Mallei, A.; Ieraci, A.; Corna, S.; Tardito, D.; Lee, F.S.; Popoli, M. Global epigenetic analysis of BDNF Val66Met mice hippocampus reveals changes in dendrite and spine remodeling genes. Hippocampus 2018, 28, 783-795. [CrossRef]

60. Bamji, S.X.; Rico, B.; Kimes, N.; Reichardt, L.F. BDNF mobilizes synaptic vesicles and enhances synapse formation by disrupting cadherin- $\beta$-catenin interactions. J. Cell Biol. 2006, 174, 289-299. [CrossRef] [PubMed]

61. Hoseth, E.Z.; Krull, F.; Dieset, I.; Mørch, R.H.; Hope, S.; Gardsjord, E.S.; Steen, N.E.; Melle, I.; Brattbakk, H.-R.; Steen, V.M.; et al. Exploring the Wnt signaling pathway in schizophrenia and bipolar disorder. Transl. Psychiatry 2018, 8, 1-10. [CrossRef] [PubMed]

62. Al-Dujaili, A.H.; Mousa, R.F.; Al-Hakeim, H.K.; Maes, M. High Mobility Group Protein 1 and Dickkopf-Related Protein 1 in Schizophrenia and Treatment-Resistant Schizophrenia: Associations with Interleukin-6, Symptom Domains, and Neurocognitive Impairments. Schizophr. Bull. 2021, 47, 530-541. [CrossRef] [PubMed]

63. Maes, M.; Delanghe, J.; Chiavetto, L.B.; Bignotti, S.; Tura, G.B.; Pioli, R.; Zanardini, R.; Altamura, C.A. Haptoglobin polymorphism and schizophrenia: Genetic variation on chromosome 16. Psychiatry Res. 2001, 104, 1-9. [CrossRef]

64. Maes, M.; Vojdani, A.; Galecki, P.; Kanchanatawan, B. How to Construct a Bottom-Up Nomothetic Network Model and Disclose Novel Nosological Classes by Integrating Risk Resilience and Adverse Outcome Pathways with the Phenome of Schizophrenia. Brain Sci. 2020, 10, 645. [CrossRef]

65. Levchenko, A.; Davtian, S.; Freylichman, O.; Zagrivnaya, M.; Kostareva, A.; Malashichev, Y. Beta-catenin in schizophrenia: Possibly deleterious novel mutation. Psychiatry Res. 2015, 228, 843-848. [CrossRef] [PubMed]

66. Dong, F.; Jiang, J.; McSweeney, C.; Zou, D.; Liu, L.; Mao, Y. Deletion of CTNNB1 in inhibitory circuitry contributes to autismassociated behavioral defects. Hum. Mol. Genet. 2016, 25, 2738-2751. [CrossRef]

67. Redies, C.; Hertel, N.; Hübner, C.A. Cadherins and neuropsychiatric disorders. Brain Res. 2012, 1470, 130-144. [CrossRef]

68. Hawi, Z.; Tong, J.; Dark, C.; Yates, H.; Johnson, B.; Bellgrove, M.A. The role of cadherin genes in five major psychiatric disorders: A literature update. Am. J. Med Genet. Part B Neuropsychiatr. Genet. 2018, 177, 168-180. [CrossRef] [PubMed]

69. O'Connor, L.; Gilmour, J.; Bonifer, C. The Role of the Ubiquitously Expressed Transcription Factor Sp1 in Tissue-specific Tran-scriptional Regulation and in Disease. Yale J. Biol. Med. 2016, 89, 513-525.

70. Mao, X.R.; Moerman-Herzog, A.M.; Chen, Y.; Barger, S.W. Unique aspects of transcriptional regulation in neurons nuances in NFkappaB and Sp1-related factors. J. Neuroinflammation 2009, 6, 16. [CrossRef]

71. Sif, S.; Gilmore, T.D. Interaction of the v-Rel oncoprotein with cellular transcription factor Sp1. J. Virol. 1994, 68, 7131-7138. [CrossRef]

72. Ryu, H.; Lee, J.; Zaman, K.; Kubilis, J.; Ferrante, R.J.; Ross, B.D.; Neve, R.; Ratan, R.R. Sp1 and Sp3 Are Oxidative Stress-Inducible, Antideath Transcription Factors in Cortical Neurons. J. Neurosci. 2003, 23, 3597-3606. [CrossRef] [PubMed]

73. Ravache, M.; Weber, C.; Merienne, K.; Trottier, Y. Transcriptional Activation of REST by Sp1 in Huntington's Disease Models. PLoS ONE 2010, 5, e14311. [CrossRef]

74. Zhao, J.-G.; Zhou, L.; Jin, J.-Y.; Zhao, Z.; Lan, J.; Zhang, Y.-B.; Zhang, Q.-Y.; Gui, J.-F. Antimicrobial activity-specific to Gramnegative bacteria and immune modulation-mediated NF-kB and Sp1 of a medaka $\beta$-defensin. Dev. Comp. Immunol. 2009, 33, 624-637. [CrossRef] [PubMed]

75. Gallego, J.A.; Blanco, E.A.; Morell, C.; Lencz, T.; Malhotra, A.K. Complement component C4 levels in the cerebrospinal fluid and plasma of patients with schizophrenia. Neuropsychopharmacology 2021, 46, 1140-1144. [CrossRef] [PubMed]

76. Rey, R.; Suaud-Chagny, M.-F.; Bohec, A.-L.; Dorey, J.-M.; D’Amato, T.; Tamouza, R.; Leboyer, M. Overexpression of complement component $\mathrm{C} 4$ in the dorsolateral prefrontal cortex, parietal cortex, superior temporal gyrus and associative striatum of patients with schizophrenia. Brain Behav. Immun. 2020, 90, 216-225. [CrossRef] [PubMed]

77. Purves-Tyson, T.D.; Robinson, K.; Brown, A.M.; Boerrigter, D.; Cai, H.Q.; Weissleder, C.; Owens, S.J.; Rothmond, D.A.; Weickert, C.S. Increased Macrophages and C1qA, C3, C4 Transcripts in the Midbrain of People with Schizophrenia. Front. Immunol. 2020, 11, 2002. [CrossRef] [PubMed]

78. Talukdar, P.M.; Abdul, F.; Maes, M.; Berk, M.; Venkatasubramanian, G.; Kutty, B.M.; Debnath, M. A proof-of-concept study of maternal immune activation mediated induction of Toll-like receptor (TLR) and inflammasome pathways leading to neuroprogressive changes and schizophrenia-like behaviours in offspring. Eur. Neuropsychopharmacol. 2021, 52, 48-61. [CrossRef] [PubMed]

79. Talukdar, P.M.; Abdul, F.; Maes, M.; Binu, V.; Venkatasubramanian, G.; Kutty, B.M.; Debnath, M. Maternal Immune Activation Causes Schizophrenia-like Behaviors in the Offspring through Activation of Immune-Inflammatory, Oxidative and Apoptotic Pathways, and Lowered Antioxidant Defenses and Neuroprotection. Mol. Neurobiol. 2020, 57, 1-17. [CrossRef] 
80. Simeonova, D.; Ivanovska, M.; Murdjeva, M.; Carvalho, A.F.; Maes, M. Recognizing the Leaky Gut as a Trans-diagnostic Target for Neuroimmune Disorders Using Clinical Chemistry and Molecular Immunology Assays. Curr. Top. Med. Chem. 2018, 18, 1641-1655. [CrossRef]

81. Simeonova, D.; Stoyanov, D.; Leunis, J.; Carvalho, A.F.; Kubera, M.; Murdjeva, M.; Maes, M. Increased Serum Immunoglobulin Responses to Gut Commensal Gram-Negative Bacteria in Unipolar Major Depression and Bipolar Disorder Type 1, Especially When Melancholia Is Present. Neurotox. Res. 2019, 37, 338-348. [CrossRef] [PubMed]

82. Maes, M.; Mihaylova, I.; Leunis, J.-C. Increased serum IgA and IgM against LPS of enterobacteria in chronic fatigue syndrome (CFS): Indication for the involvement of gram-negative enterobacteria in the etiology of CFS and for the presence of an increased gut-intestinal permeability. J. Affect. Disord. 2007, 99, 237-240. [CrossRef] [PubMed]

83. Krynicki, C.R.; Dazzan, P.; Pariante, C.M.; Barnes, N.M.; Vincent, R.C.; Roberts, A.; Giordano, A.; Watson, A.; Suckling, J.; Barnes, T.R.; et al. Deconstructing depression and negative symptoms of schizophrenia; differential and longitudinal immune correlates, and response to minocycline treatment. Brain, Behav. Immun. 2021, 91, 498-504. [CrossRef]

84. Maes, M.; Fišar, Z.; Medina, M.; Scapagnini, G.; Nowak, G.; Berk, M. New drug targets in depression: Inflammatory, cellmediated immune, oxidative and nitrosative stress, mitochondrial, antioxidant, and neuroprogressive pathways. And new drug candidates-Nrf2 activators and GSK-3 inhibitors. Inflammopharmacology 2012, 20, 127-150. [CrossRef]

85. Maes, M. Nooit Meer Moe; Paperback, Zorrobooks: Brugge, Belgium, 2011; ISBN 9789461680013. 